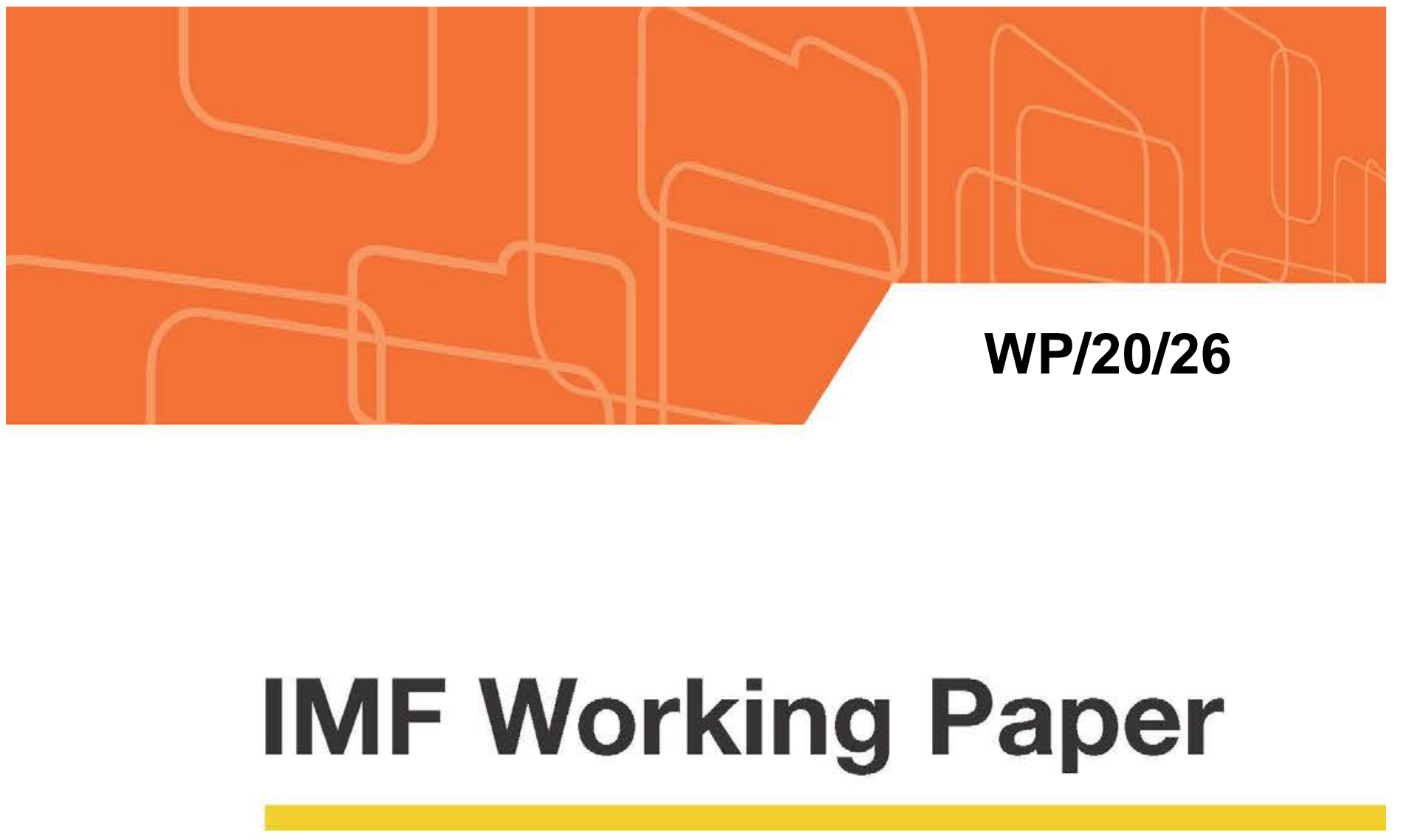

\title{
Monetary Policy Implementation: Operational Issues for Countries with Evolving Monetary Policy Frameworks
}

\author{
by Nils Mæhle
}

IMF Working Papers describe research in progress by the author(s) and are published to elicit comments and to encourage debate. The views expressed in IMF Working Papers are those of the author(s) and do not necessarily represent the views of the IMF, its Executive Board, or IMF management. 


\title{
IMF Working Paper
}

Monetary and Capital Markets Department

\section{Monetary Policy Implementation: Operational Issues for Countries with Evolving Monetary Policy Frameworks}

\section{Prepared by Nils Mæhle ${ }^{1}$}

Authorized for distribution by Jihad Alwazir

February 2020

\section{IMF Working Papers describe research in progress by the author(s) and are published to elicit comments and to encourage debate. The views expressed in IMF Working Papers are those of the author(s) and do not necessarily represent the views of the IMF, its Executive Board, or IMF management.}

\begin{abstract}
This paper discusses operational issues for countries that want to reform their monetary policy frameworks. It argues that stabilizing short-term interest rates on a day-to-day basis has significant advantages, and thus that short-term interest rates, not reserve money, in most cases should be the daily operating target, including for countries relying on a money targeting policy strategy. The paper discusses how a policy formulation framework based on monetary aggregates can be combined with an operational framework that ensures more stable and predictable short-term rates to enhance policy transmission. It also discusses how to best configure an interest-rate-based operational framework when markets are underdeveloped and liqudity management capacity is weak.
\end{abstract}

JEL Classification Numbers: E4, E42, E43, E5, E51, E52, E58

Keywords: monetary policy operations, monetary targeting, monetary policy transmission, liqudity management, interest rate determination

Author’s Email Address: nmaehle@imf.org, maehlenils@gmail.com

\footnotetext{
1 The paper draws on interaction and discussions with external experts and policymakers during many MCM technical assistance missions, and benefits from comments from a large number of IMF colleagues.
} 


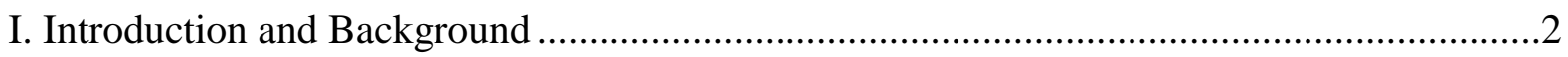

II. The Choice of Operating Target for Monetary Policy ……...................................................

A. General Considerations .........................................................................................4

B. Policy Transmission and the Operating Target for Monetary Policy..........................6

III. Flexible Monetary Targeting: Combining Operations that Steer and Stabilize Interest Rates with a Continued Role for Money Targets....................................................................

A. Introduction and Background..............................................................................

B. Flexible Monetary Targeting Option 1....................................................................

C. Flexible Monetary Targeting Option 2................................................................13

IV. Configuration of Interest-Rate-Focused Operational Frameworks in LLMICs .................14

A. Introduction and General Considerations ................................................................14

B. The Conventional Flexible-Price Fixed-Quantity System .......................................15

C. The Floor System .....................................................................................

D. The Fixed-Rate Full-Allotment System.............................................................21

E. The Optimal Width of the Interest Rate Corridor .....................................................22

F. Implications for Central Bank Costs......................................................................23

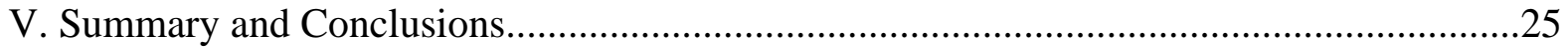

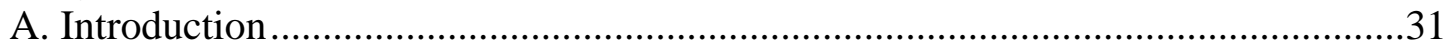

B. The Individual Bank Model .................................................................................32

C. The Aggregate Market Model.............................................................................37

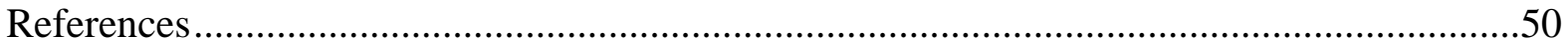

Boxes

1. The Demand for Reserve Balances and the Role of Standing Facilities .............................17

Figures

1. Monetary Policy Operations: Interest Rate Volatility and Deviation from the Policy Rate..2

2. The Monetary Policy Framework: Instruments, Targets, and Objectives ..............................5

3. Monetary Policy Transmission Channels .............................................................................6

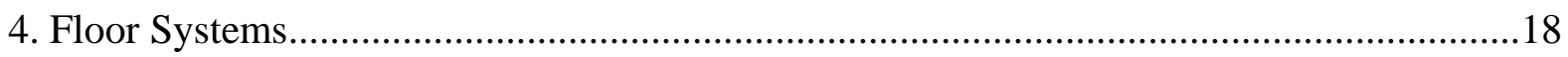

Table

1. Interest Rate Corridor Width in Selected Countries ............................................................23

Appendices

I. Interest Rate Volatility and Alignment in Selected Countries ..............................................27

II. Demand for Reserve Balances, Uncertainty, and the Role of Standing Facilities ...............31

III. Monetary Policy Transmission Channels ............................................................................40 


\section{INTRODUCTION AND BACKGROUND}

Shortcomings in operational frameworks and weak liquidity management are major obstacles for effective monetary policy implementation in many low- and lower-middle income countries (LLMICs). The daily variation in overnight interbank rates is large in many LLMICs, in stark contrast to in advanced countries (Figure 1 and Appendix I). This is particularly true for countries with base (or reserve) money as the operating target but has also been the case in some countries that use a policy rate to signal the policy stance. ${ }^{1,2}$ Interbank rates have not been aligned with the policy rate in many of the LLMICs that use a policy rate to signal the policy stance. The spread has been at times both large and semipersistent, with periodic large shifts, indicating large and systematic differences between the de jure and the de facto policy stance as reflected in the interbank market rates. For some countries, the difference is so large and the relationship between them so weak that the policy rate may have had little effect on commercial banks' liquidity management and pricing decisions. The result has been high short-term liquidity risk, a dilution of policy signals, and, therefore, a weak monetary policy transmission. In these circumstances, it is also difficult to build central bank credibility. ${ }^{3,4}$

\section{Figure 1. Monetary Policy Operations: Interest Rate Volatility and Deviation from the Policy Rate}
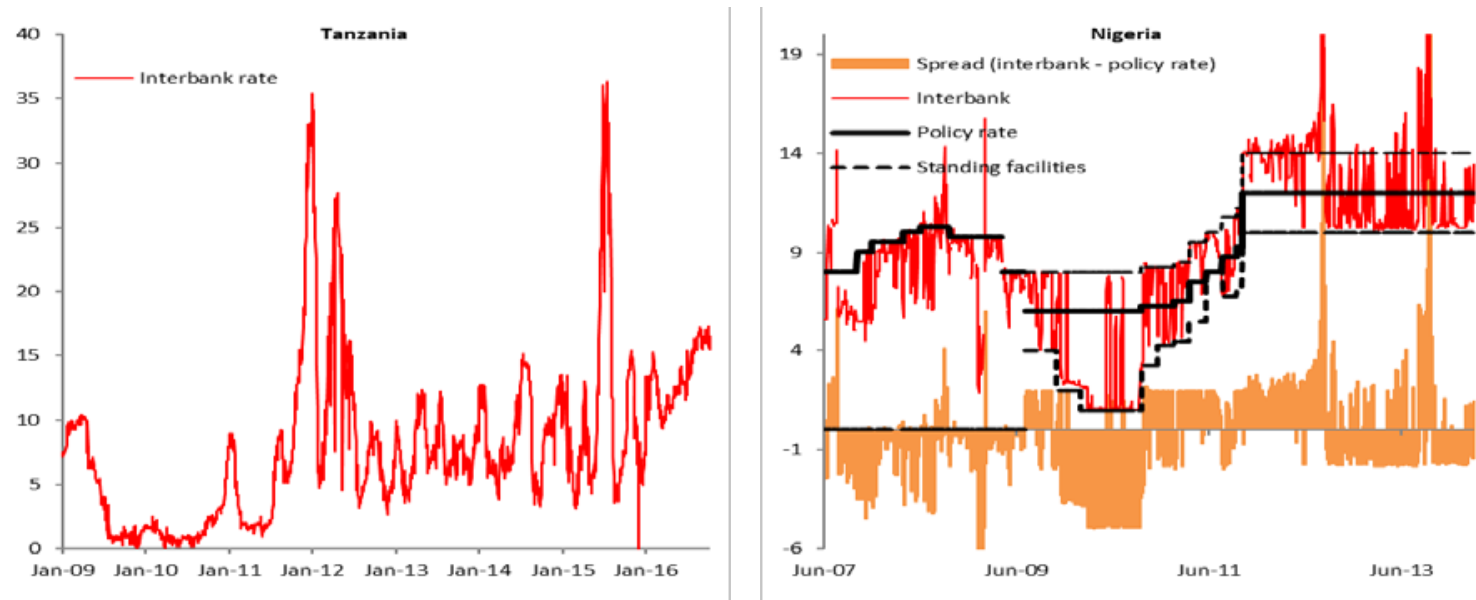

Sources: Central banks of Nigeria and Tanzania.

\footnotetext{
${ }^{1}$ For example, in Kenya, Malawi, Nigeria, Uganda (before 2012), and Zambia (Appendix I).

2 The term "policy rate" in this paper is reserved for a central bank rate that is meant to signal the policy stance. It does not cover central bank discount and standing facility rates-even when locally referred to as the "Bank Rate”-in countries with reserve money as the operating target.

${ }^{3}$ Cottarelli and Kourelis (1994) found that policy rates that were not in line with the de facto policy stance, as reflected in money market rates, reduced the transmission from money market rates to retail lending rates.

4 The high short-term liquidity risk, unclear, inconsistent, and possibly irrelevant policy signals may also weaken bank competition by creating arbitrage opportunities that favor larger banks with the analytical skills and capacity to understand the logic of the central bank's operations, and thereby further weaken transmission.
} 
A clearer focus on operational issues and the relationship between the operational framework and monetary policy strategy in the discussion of how to reform LLMICs' monetary policy frameworks may help to overcome this apparent disconnect. The existing literature mainly discusses the monetary policy strategy and the role of inflation, monetary, and exchange rate targeting; the preconditions for moving to inflation targeting (IT); and technical operational issues in advanced countries with short-term interest rates as the operating target. There has been less focus on the relationship between the operational framework and the monetary policy strategy; and on the specific operational issues in LLMICs, where, typically, markets are less developed and the capacity for producing accurate short-term liquidity forecasting is weak. A greater focus on operational issues would help to improve the effectiveness of monetary policy in many countries with a money-targeting policy strategy or with evolving monetary policy regimes.

This paper seeks to fill this gap. It discusses three critical issues for countries wanting to reform their monetary policy frameworks and move away from an excessive reliance on monetary aggregates:

- How to choose an operating target for central banks' daily liquidity management, in countries where (1) monetary aggregates traditionally have played a central role in guiding and implementing monetary policy; and (2) financial markets are underdeveloped and the policy transmission and the direct interest rate channel are weak.

- How countries that want a continued role for monetary targets in their policy strategy can combine this with an operational framework that ensures more stable and predictable short-term interest rates.

- How to best configure an interest-rate-focused operational framework in LLMICs, and the pros and cons of alternative configurations and how the choice might depend on the policy framework, the degree of market development, and the central bank's liquidity forecasting capacity, and how the configuration may hamper or foster the development of security markets.

This paper thus complements two recent IMF papers on evolving monetary policy frameworks in LLMICs. Laurens and others (2015) argue for the use of transitional arrangements that rely to a varying degree on both price- and quantity-based targets and signals to implement, formulate, and communicate monetary policy, as countries strive to modernize their monetary policy frameworks and move toward IT. They argue for (1) continued but flexible reliance on monetary analysis and the use of broad money as an intermediate target when reliable inflation forecasts are absent; and (2) the use of monetary analysis and monetary aggregates as a supplement and a safeguard, or cross-checking device, once robust economic analysis and inflation forecasting capacity has been developed. A more flexible use of monetary aggregates to guide the setting of the policy stance would allow for a more interest-rate-focused operational framework. IMF (2015) laid out a set of principles that characterize an effective monetary policy framework, evaluated where LLMICs stood 
relative to these principles, and provided guidance on how they can make progress and improve their regimes along various dimensions.

\section{The Choice of Operating Target for Monetary Policy}

\section{A. General Considerations}

The operating target is a variable that can be sufficiently controlled by the central bank to serve as a guide for its day-to-day operations, ${ }^{5}$ and that can effectively support the achievement of the primary monetary policy objective. The operating target has typically been reserve money under monetary targeting (MT) as practiced by many LLMICs. Under IT, it has been a short-term market interest rate.

When considering the choice of operating target, it is essential to distinguish it from the other elements of the monetary policy framework (Figure 2). A fully specified monetary policy framework comprises:

- The primary objective of monetary policy, which is typically price stability, including for countries that follow a MT strategy. ${ }^{6}$

- $\quad$ The policy strategy and policy formulation framework, which helps the central bank formulate the policy stance and set the level of the operating target so as to achieve the primary policy objective. Intermediate targets for a monetary aggregate help map policy objectives to operations under a MT policy strategy. ${ }^{7}$

- $\quad$ The operational framework, comprising the operating target and the monetary instruments the central bank uses to manage excess reserves ${ }^{8}$ and the conditions in the interbank money market necessary to achieve its operating target. The instruments are tools used by the central bank over which it has full control. The main tools are standing lending and deposit facilities, which commercial banks can freely access at their own discretion, and open market operations (OMOs).

\footnotetext{
${ }^{5}$ The operations have to be daily without reserve averaging but can be slightly less frequent with reserve averaging.

${ }^{6}$ Most money-targeting central banks have price stability as the overriding mandate and may derive their money targets from an explicit and sometimes published numerical inflation target. That is, most MT and IT central banks are, in practice, targeting inflation.

7 The inflation forecasting process serves a similar role under inflation targeting.

${ }^{8}$ In this paper, excess reserves are defined as all liquid balances commercial banks have on their various reserve, overnight, and current accounts at the central bank in excess of required reserves, irrespective of whether all of these funds count against the reserve requirement. It excludes term deposits. This is a wider definition than found in some papers, where the term may only refer to unremunerated funds left in banks' reserve accounts and not funds transferred to separate interest-earning overnight deposit accounts.
} 
While a money-targeting policy strategy is often closely associated with reserve money as the operating target, this is not how it was practiced in advanced countries. Most, advanced countries explicitly, or de facto, used short-term interest rates as the operating target when they followed a money-targeting policy strategy-i.e., the monetary aggregate target was de facto an intermediate target. ${ }^{9}$

Figure 2. The Monetary Policy Framework: Instruments, Targets, and Objectives

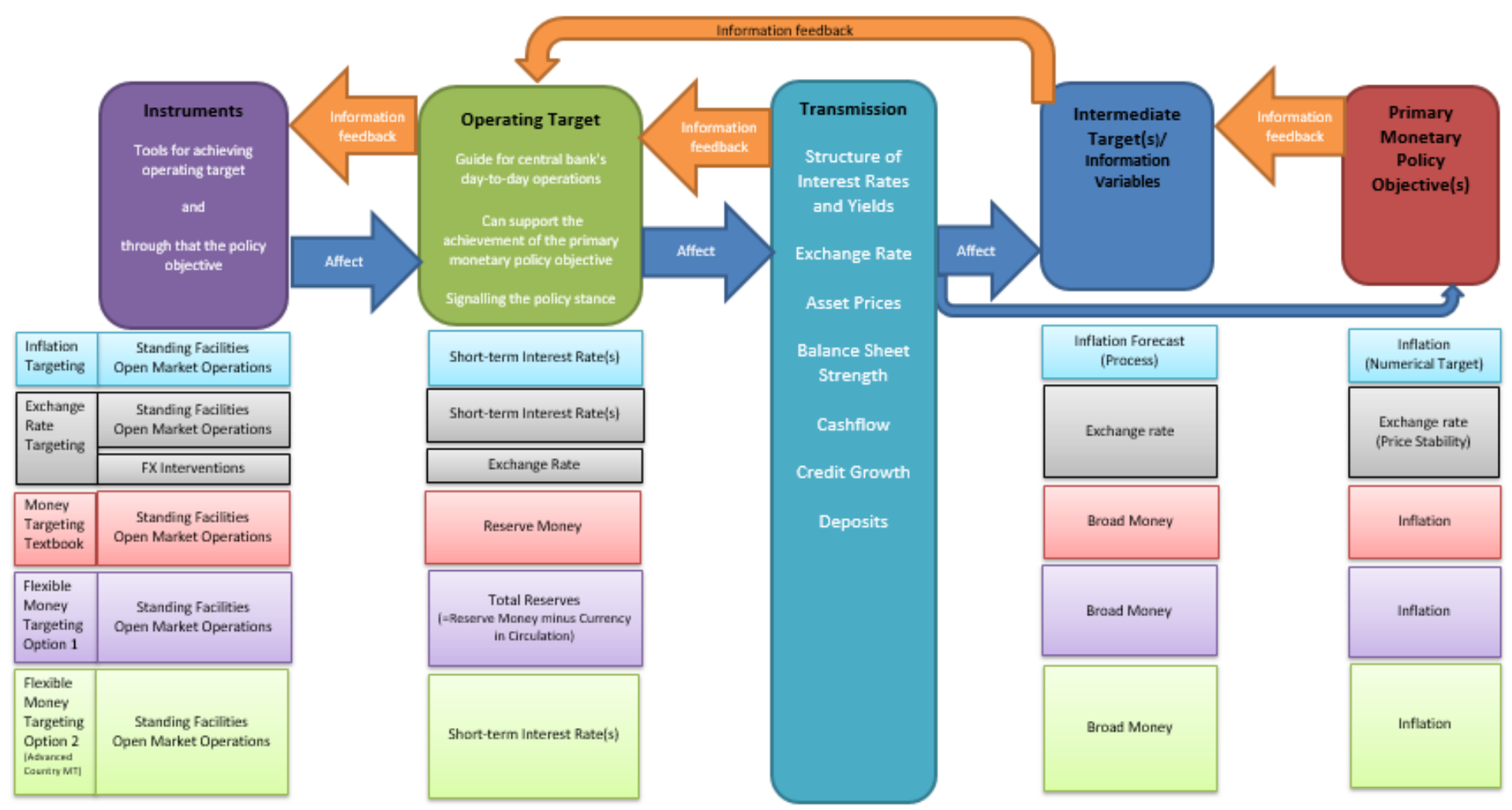

\footnotetext{
${ }^{9}$ Including Germany (Batten and others, 1989; Bernanke and Mihov, 1996; Mishkin and Posen, 1997; Benati and Goodhart, 2011), Canada (Batten and others, 1989; Freedman, 2000a), Japan (Batten and others, 1989) and UK (Batten and others, 1989; Tucker, 2004). See also Bindseil (2004a, 2004b, 2011) for a discussion of this and the rise and fall of the reserve position doctrine, as well as Sellon (1982), Friedman (2000), Ireland (2000), Poole (2000), and Bindseil and Wuertz (2006).
} 


\section{B. Policy Transmission and the Operating Target for Monetary Policy}

The central thesis of this paper is that short-term interest rates should in most cases be the operating target for day-to-day monetary policy operations, even in countries that rely on a money-targeting policy strategy. There are two main reasons why this should lead to an improved transmission of monetary policy:

- Monetary policy operations mainly work through their impact on market interest rates and yields, liquidity risk and risk premiums, the exchange rate, and expectations, as illustrated in Figure 3 and discussed in detail in Appendix III. ${ }^{10}$

- Policy transmission to the rates that influence private sector behavior-rates on longerterm securities, deposit, and lending rates — should be stronger when monetary operations ensure stable and predictable short-term rates. As also argued in IMF (2015), then discrete changes in the policy rate should have a greater impact on banks' pricing behavior as they will have more confidence that changes in the structure of interest rates will be sustained.

Figure 3. Monetary Policy Transmission Channels

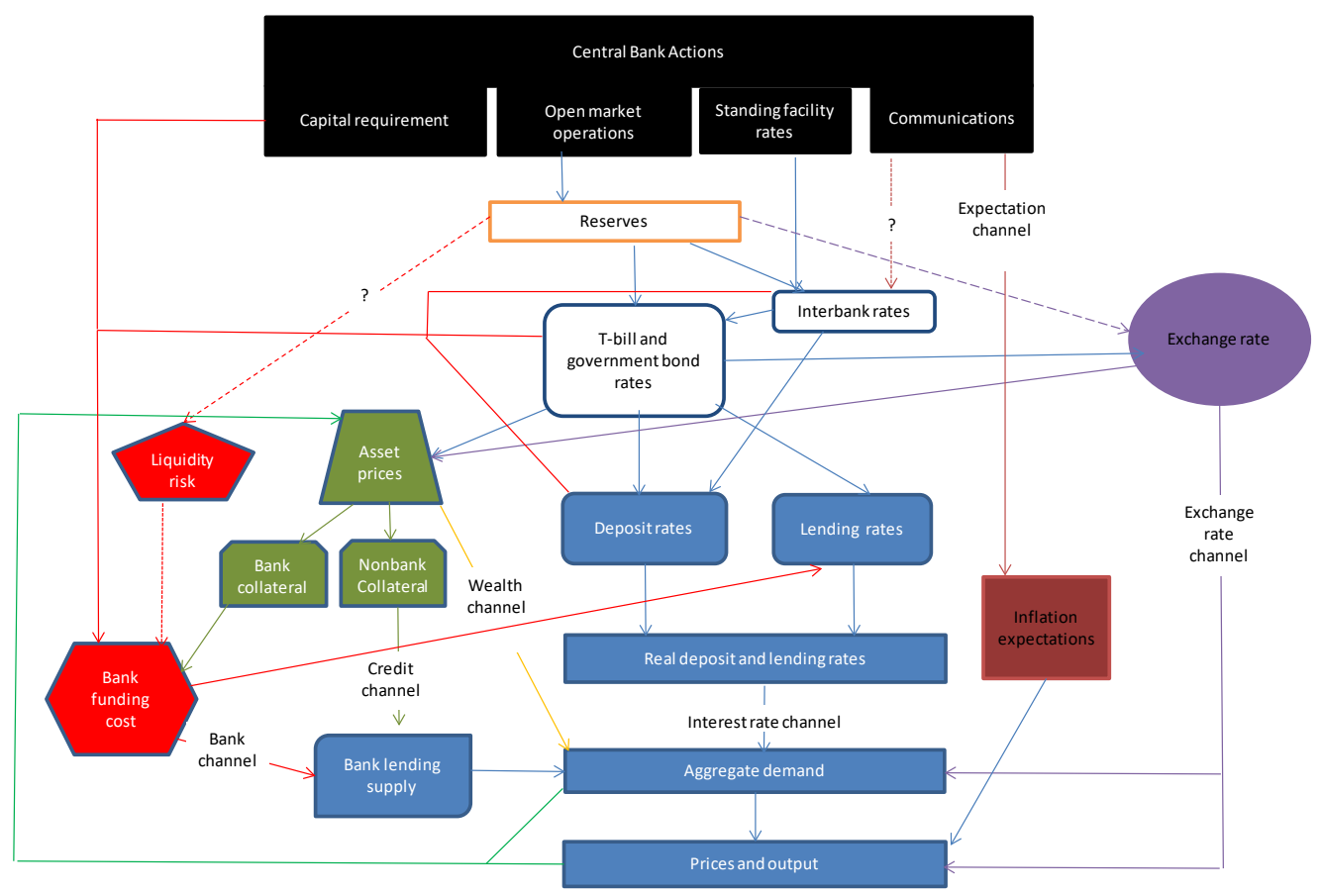

\footnotetext{
${ }^{10}$ This does not mean that what is commonly referred to as the (narrow) "interest rate channel" dominates, or is particularly strong, but that most of the transmission channels discussed in the literature-including the credit, bank lending, bank capital, and wealth channels-work through the impact of monetary policy on interest rates and asset yields, or by amplifying the effect of changes in these through the impact of policy on asset prices, credit risk, and banks' risk appetite (see also Bernanke and Gertler, 1995, page 28, for a similar observation that the credit channel is not a distinct, free-standing channel, but rather a set of factors that amplify and propagate conventional interest effects).
} 
Thus, to facilitate an effective policy transmission, policy operations need to ensure: (1) consistency between policy signals and actions; and (2) that banks can predictably place surplus liquidity with, and obtain short-term funding from, each other or the central bank at rates that are reasonably stable and predictable. This is true even in economies in which key financial markets and the yield curve are not yet well developed. Indeed, in such economies, operations that meet the two criteria stated above provide an essential foundation for the development of financial markets.

Clear policy signals that guide current expectations of future short-term rates can improve transmission along the yield curve, to deposit and lending rates, and to the exchange rate, and thus to consumption and investment demand. However, for signaling to have this effect it needs to both represent a credible signal of future central bank actions and a relevant signal. The latter requires that banks predictably can obtain or place funds at the signaled short-term rate. Large spreads between the policy rate and short-term market rates imply that the policy rate is neither a credible nor a relevant signal of central bank actions. Such signals may be worse than no signals, and risk weakening policy transmission. Highly volatile short-term rates are hard to predict and do not provide a reliable basis for longer-term decisions, such as the pricing of loans and securities, and can impede financial market development.

In sum, the central bank's ability to influence the economy stems from its ability to control short-term interest rates and, when markets are not functioning, liquidity risk and the implied "shadow price" on excess reserves. Its ability to control short-term interbank rates is due to its control over the total stock of reserve balances (i.e., commercial bank deposits at the central bank) and the terms for borrowing or depositing such funds with it - that is, the terms of its standing lending and deposit facilities. ${ }^{11,} 12$

The relationship between central bank interest rates and commercial bank reserve balances deserves further explanation. Commercial banks can use reserve balances for interbank transactions and for transactions with the central bank and government. They cannot, however, lend them out or transfer them to any entity that does not have an account with the central bank. ${ }^{13}$ Banks typically receive, and make, a number of interbank payments each day, including payments to settle retail transactions. While the net of these interbank payments and transactions with the central bank and government may be close to zero, there is always a

\footnotetext{
${ }^{11}$ Standing facilities are short-maturity central bank lending and deposit facilities where the central bank stands ready to transact with banks on demand and in unlimited amounts, provided certain conditions are met. The lending facility is critical to ensuring the smooth functioning of the payment system and for reducing the risk of a liquidity crisis.

${ }^{12}$ Instead of having a separate overnight (time) deposit account into which banks, at the end of the day, would transfer excess funds in order to earn interest, some central banks just remunerate any excess balances held in banks' reserve or settlement accounts. Because both arrangements effectively have the same impact on the interbank market and on liquidity risks, in this paper the term "deposit facility" is used for both.

${ }^{13}$ This is in contrast to how monetary policy is often depicted in textbooks, as working through a quantity-based money-multiplier process. See among others Disyatat (2008), Keister and McAndrews (2009), Bernhardsen and Kloster (2012), and McLeay, Radia, and Thomas (2014) and Appendix III of this paper.
} 
risk for the market in aggregate, or for individual banks, ending the day short of reserves or with excess reserves. Banks that end the day short must access the central bank's standing lending facility (if available) to avoid falling short on interbank payments or failing reserve requirements. This can be costly for the bank, but so can holding large reserve balances at the central bank that could have been lent to banks that were short.

Against this background, the central bank's OMOs influence the risk of the market ending the day short or long, while the terms of the standing facilities (and the penalties for failing reserve requirements) determine the cost. As explained in Appendix II, the risk of individual banks, or the market in aggregate, ending the day short or long and the terms on the standing facilities determine the overnight interbank market rate when there is a well-developed interbank market, and, also, the corresponding implied shadow price on reserves when there's no, or a poorly functioning, interbank market. Central bank actions that change this (market or shadow) price on reserve balances constitute the crucial first stage of the transmission of monetary policy. ${ }^{14}$

Using reserve money as the operating target for day-to-day policy operations can severely hamper policy transmission and market development. As illustrated in Figure 1 and Appendix I, it is often associated with highly volatile and unpredictable short-term market rates. This can introduce noise into the monetary policy signal and impede market pricing of longer-term financial assets and liabilities. And, as noted, high volatility also impedes the development of markets for these instruments, and of the yield curve, thereby hampering policy transmission. ${ }^{15}$ Where a yield curve exists, higher volatility can steepen it and increase liquidity risk premiums. ${ }^{16}$

\section{Flexible MONETARY TARgeting: COMBININg OPERATIONS THAT STEER AND STABILIZE INTEREST RATES WITH A CONTINUED ROLE FOR MONEY TARGETS}

\section{A. Introduction and Background}

Operations that ensure more stable and predictable short-term rates can be compatible with retaining a role for monetary aggregates. Laurens and others (2015) discuss two broad transitional arrangements-Flexible Monetary Targeting (FMT) and Enhanced Monetary Policy Analysis (EMPA) - that countries might find useful as they transition to a framework closer to IT. The EMPA is similar to the ECB's two-pillar approach, where monetary aggregates mainly serve as indicators and cross-checks. FMT, in contrast, retains a role for

\footnotetext{
${ }^{14}$ See Appendix III for a detailed discussion of the monetary policy transmission channels.

${ }^{15}$ Cottarelli and Kourelis (1994) found that a high degree of random fluctuation in money market rates was associated with sticky retail lending rates and weak policy transmission, as policy signals would be lost in the noise of random movements.

${ }^{16}$ It may also result in a hoarding of reserves and other liquid assets, and lower interbank trading.
} 
money targets while also providing flexibility for the day-to-day management of excess reserves to facilitate a relatively smooth development of short-term interest rates.

Laurens and others (2015) outline two broad options for FMT: option 1, where operations continue to focus on keeping quantities on a path consistent with meeting reserve money targets, but where total reserves, not reserve money, is the operating target; and option 2, where money aggregates have no operational role and are only used as intermediate targets (possibly together with other forward-looking indicators and analysis) to guide the setting of short-term interest rates, which serve as the de facto operating target. FMT option 1 is complicated and difficult to communicate but helps remove two of the main sources for the high interest rate volatility associated with the use of reserve money as the operating target. It is mainly relevant for countries facing severe fiscal dominance, limited independence, and/or political or public pressure to keep interest rates too low, and thus cannot openly communicate that monetary policy is about setting the proper level of short-term interest rates. As argued in IMF (2015), reserve money targeting may then allow the central bank to tighten policy without taking responsibility for interest rate increases. ${ }^{17}$ FMT option 2 in contrast is simple. It is similar to how most advanced countries operated when they followed a money-targeting policy strategy. These two options are spelled out more fully in Sections B and $\mathrm{C}$ below.

\section{B. Flexible Monetary Targeting Option 1}

Countries that want to focus operations on keeping quantities on a path consistent with meeting reserve money targets can take steps to reduce the day-to-day volatility in short-term interest rates. Two of the main sources for high-frequency volatility in short-term interest rates associated with the use of reserve money as the operating target are: (1) an excessive focus on achieving end-period targets with little attention to managing excess reserves on a day-to-day basis, or to how these targets relate to the day-to-day management of excess reserves, which can result in high end-period liquidity and interest rate volatility; and (2) focusing operations on keeping reserve money on a predetermined path on a daily basis. In the second case, daily swings in currency holdings would generate opposite swings in total and in excess reserves, and corresponding swings in short-term interest rates, particularly if banks are also required to meet reserve requirements on a daily basis. These two sources of high-frequency volatility can be addressed by:

- $\quad$ Setting reserve money targets over a prespecified period (for example, quarterly), on average terms, and possibly within a band. This can help shift the focus from achieving end-period targets to ensuring that excess reserves on average are consistent with achieving the target, while allowing reserve money to vary from day to day in order to keep excess reserves and short-term market interest rates reasonably stable.

\footnotetext{
${ }^{17}$ Bindseil (2004a, 2004b, 2011) argues that this may be a main reason for the past popularity of the reserve targeting doctrine.
} 
- Setting a path for total reserves that is consistent with the longer-term reserve money target and using this derived path for total reserves as the operating target. This would help insulate the interbank money market from daily swings of currency in circulation and remove that source of high-frequency volatility in excess reserves and short-term interest rates.

Active liquidity management to offset autonomous changes in liquidity conditions would be needed to keep excess reserves and interest rates stable and total reserves on the path consistent with the reserve money target. Under this operational framework, the central bank would use flexible-rate fixed-quantity open-market operations both to offset the impact of autonomous factors ${ }^{18}$ on excess reserves and to keep total reserves on target. ${ }^{19}$ Achieving this would require accurate short-term forecasts of the autonomous liquidity factors, as well as lengthening the liquidity forecasting horizon to cover the entire horizon of the medium-term reserve money target.

This quantity-based operational framework can be combined with an interest rate corridor to cap changes in short-term interbank market interest rates. In all corridor systems, an overnight standing lending facility is combined with an overnight standing deposit facility to provide a corridor for the overnight interbank market rate to move within in response to changing liquidity conditions. The standing facilities will help reduce interest rate volatility and liquidity risk. The rates on these facilities should be fixed and not tied to any market rate, and access to them should be unlimited and automatic at the initiation of banks in order to provide a firm ceiling and floor for the overnight interbank market rate. ${ }^{20}$

This approach would not, however, be compatible with using a central bank policy rate to signal the policy stance. For a central bank rate to de facto signal the policy stance it must serve as the de facto operating target and signal the central bank's commitment to use its OMOs to steer a short-term interbank market rate close to the target. However, as a rule, it is

\footnotetext{
${ }^{18}$ Autonomous factors are the changes in the central bank's balance sheet that inject or withdraw reserves other than those related to the central bank's monetary policy operations. The main factors are currency in circulation, the net government position with the central bank, and the central bank's foreign exchange interventions.

${ }^{19}$ The operations would have to be daily in a system without reserve averaging, while two to three operations within the maintenance period (MP) — one at the first day of the MP, possibly one in the middle, and a finetuning operation at the end of the MP — could in principle be sufficient, when averaging over the MP is allowed. Reserve averaging gives banks flexibility in determining when to hold reserves during the MP to meet their reserve requirements and makes short-term market rates less sensitive to changes in the stock of reserves. It thereby also helps to reduce the tension between the day-to-day liquidity operations needed to stabilize excess reserves (and keeping short-term rates stable) and the liquidity operations required over time to meet the reserve money target.

${ }^{20}$ The standing lending facility should also be collateralized, and with appropriate haircuts applied, to safeguard the central bank against credit risks. The collateral pool must be sufficiently wide so that banks that meet the liquidity requirements can freely access it for the lending facility to provide a firm ceiling for the overnight market interest rate.
} 
not feasible to simultaneously operate with both a short-term market interest rate and total reserves as the target for the central bank's daily liquidity management operations. ${ }^{21}$ Signals that are not acted upon risk undermining central bank credibility and weakening policy transmission.

The interest rate corridor may have to be periodically repositioned to maintain control over quantities and to prevent short-term market rates from being persistently at the floor or ceiling. Rates persistently close to or at the corridor ceiling would tend to correspond with extensive commercial bank recourse to the lending facility and thus reduced central bank's ability to lower growth in total reserves and reserve money. Any attempt to slow money growth through OMOs to reduce liquidity injections or mop up excess reserves would in this situation just increase banks use of the lending facility. To reduce money growth, the central bank would instead have to move the corridor up, so that short-term interest rates can increase further, which should slow credit growth and deposit creation, and, by implication, slow growth in reserve money and required reserves. ${ }^{22}$ Similarly, short-term interbank rates persistently at the floor when total reserves are on or below target would suggest a need to shift the corridor down to allow short-term rates to fall further and support a decline in longer rates and increased credit and deposit growth. ${ }^{23},{ }^{24}$ Any attempt to increase excess reserves and money growth through OMOs would in this situation just increase banks use of the deposit facility. This repositioning of the corridor could serve as a signal to the market that the policy stance is being tightened or loosened and thereby help improve transparency and communication. ${ }^{25}$

The width of the corridor under this option would have to be chosen with some care. A narrow corridor would help keep interest rates reasonably stable and thereby help improve the clarity of the policy signal. However, a narrow corridor would also require a more frequent repositioning to ensure that quantities over time evolve as targeted. It would also increase the likelihood that corridor shifts may have to be frequently reversed, which could muddle the policy signal and undermine the market's confidence in the policy framework. The corridor may be set relatively wide initially to provide the central bank with the flexibility needed to meet its reserve money target and to reduce the need for frequent

\footnotetext{
${ }^{21}$ Having an internal target for the interbank rate to guide the OMOs may be helpful, though, in order to gain experience with how to eventually operate a system with a short-term market rate as the operational target.

${ }^{22}$ Capping access to the lending facility instead in this situation would increase liquidity risk and market interest rates, which would also slow credit and deposit creation and money growth. It could, however, also result in a liquidity crisis as well as encourage reserve hoarding and thereby reduce monetary policy transmission.

${ }^{23}$ This would tend to go together with extensive commercial bank recourse to the deposit facility as well.

${ }^{24}$ With no, or poorly functioning, interbank markets, the degree of banks' recourse to the lending or deposit facilities could be a better signal than interbank rates for the need to shift the corridor up or down.

${ }^{25}$ It is critical to ensure that changes in the standing facility rates are consistent with the liquidity operations so as to avoid a situation where market rates end up moving in the opposite direction of the standing facility rates, which would send conflicting signals about the intended change in the policy stance.
} 
repositioning of the corridor. However, it should subsequently be narrowed, as the central bank gains experience in operating the framework and improves its liquidity forecasting capacity, to better stabilize the interbank rate and strengthen the price signal.

Periodic reassessment of the key parameters and assumptions of the monetary program would allow for adjusting the liquidity targets. The default under FMT option 1 would be to adhere to the average reserve money target and implied targeted path for total reserves and move the interest rate corridor when rates persistently hit the floor or ceiling. However, rates persistently close to the corridor floor or ceiling could indicate a need for reassessing the program assumptions. This periodic reassessment could draw on a broad range of information and analyses, including economic analysis and modeling.

This quantity-based framework creates an automatic feedback loop from broad money growth to short-term market rates. ${ }^{26}$ Liquidity conditions would tighten (loosen) - that is, excess reserves would decline (increase) — and interbank market rates ${ }^{27}$ be pushed up (down) if required reserves were growing faster (slower) than the target for total reserves. ${ }^{28}$ Because reserve requirements typically are set relative to total or local currency deposits, which constitute the bulk of broad money and therefore are closely correlated with it, an abovetarget growth in required reserves would tend to go together with an above-target growth in broad money as well.

This automatic feedback loop constitutes the main advantage of this quantity-based operational framework. Although complicated and possibly difficult to communicate, the focus on quantities instead of on interest rates can help ensure policy discipline and facilitate keeping interest rates as high as needed for ensuring low and stable inflation when faced with severe fiscal dominance or political pressure to keep interest rates too low. However, this automatic feedback loop could also cause shifts in broad money growth that is not correlated with future inflation to result in unwarranted changes in short-term interest rates. It would also automatically transmit to short-term interest rates any lower-frequency volatility in broad money (and deposits) via corresponding swings in required reserves. Thus, interest rates can be more volatile and policy transmission weaker than a under a fully interest-ratebased operational framework.

\footnotetext{
${ }^{26}$ Similarly, Gray (2011) notes that using control over reserve money to guide credit growth in a fiat money system in practice is an indirect way of using interest rates.

${ }^{27}$ Or the shadow price on short-term liquidity in the case of no, or a poorly functioning, interbank money market, as discussed above.

28 The definition of total reserves and of reserve money for this purpose should include all liquid balances commercial banks have on their various accounts at the central bank, including the balances on their interestearning overnight deposit accounts, but not non-liquid deposits, such as one- to two-week certificates of deposit.
} 


\section{Flexible Monetary Targeting Option 2}

A fully interest-rate-based operational framework can be combined with a role for (broad) money aggregates as intermediate targets, or information variables, to guide the interest rate setting. As noted, this is what most advanced countries did when they followed a moneytargeting policy strategy. Shifting from quantities to a short-term interest rate as the operating target would allow for using a policy rate to signal the policy stance. If combined with effective liquidity management operations that align short-term market rates with the target, this should help strengthen policy communication and transmission.

This FMT option 2 is equivalent to using a money-based instrument rule for adjusting the policy rate and operating target when money growth deviates from target:

$$
\Delta i_{t}=\mathrm{f}\left(\dot{\mathrm{m}}_{\mathrm{t}-1}-\dot{\mathrm{m}}_{\mathrm{t}-1}^{*}\right)
$$

Where $\dot{\mathrm{m}}_{\mathrm{t}-1}$ is the observed money growth and $\dot{\mathrm{m}}_{\mathrm{t}-1}^{*}$ is the target growth assumed consistent with keeping inflation on target. ${ }^{29,} 30$

Or, better, setting the policy rate in line with the following forward-looking targeting rule:

$$
i_{t}=\varphi \mathrm{i}_{\mathrm{t}}^{*}+(1-\varphi) \mathrm{i}_{\mathrm{t}-1}
$$

Where $\mathrm{i}_{\mathrm{t}}^{*}$ is the estimated rate that ensures that $E_{t-1}\left(\dot{\mathrm{m}}_{\mathrm{t}} \mid \mathrm{i}_{\mathrm{t}}\right)=\dot{\mathrm{m}}_{\mathrm{t}}^{*} \cdot{ }^{31}$

The automatic feedback loop from money targets to short-term interest rates under FMT option 1 is replaced by an information feedback loop under this option 2. This option provides less political cover to adjust interest rates as needed than does option 1 . However, it provides more flexibility to factor in the insight from other analytical tools and indicators about the inflation outlook and whether interest rates need to be adjusted to ensure that inflation over the medium term remains properly anchored. This approach could therefore facilitate a gradual transition to a monetary policy framework where economic analysis and inflation forecasting using multiple tools and approaches over time replace single-variable intermediate targets for determining the level of interest rate adjustment needed to achieve the policy objective. It could also lay the groundwork for the transition to an interest-rate focused operational framework, and eventually to an inflation targeting policy framework.

\footnotetext{
${ }^{29}$ When following a similar rule, Germany derived the broad money growth target based on a target for (unavoidable) inflation and an estimate of the growth in long-run potential output over the coming year (Mishkin and Posen, 1997). This differs from the practice in many LICs where the money growth target typically is based on forecasts for output and sometimes also for inflation. The monetary program risks becoming circular and not providing a nominal anchor if the money growth target is based on forecasts for inflation, which in turn is based on money growth.

${ }^{30}$ While this interest rate rule is backward-looking with respect to money growth, it would be forward-looking with respect to inflation if broad money growth is correlated with future inflation.

31 This is the interest rate rule used by McCallum (1981) to demonstrate that price level determination is feasible with an interest rate policy rule under rational expectations, thereby refuting the Sargent-Wallace (1975) result. It is also similar to the money growth forecasting rule discussed in Svensson (1997).
} 
The role of monetary aggregates versus modeling and other analytical tools in guiding the setting of short-term interest rates should depend on the relative accuracy of their signals about future inflation developments, absent a policy adjustment.

\section{CONFIGURATION OF INTEREST-RATE-Focused OpERATIONAL FraMEWORKS IN LLMICs}

\section{A. Introduction and General Considerations}

Several different configurations of an interest-rate-focused operational framework are possible. In all cases, the centerpiece is a policy rate that serves as the operating target for a short-term interbank market rate-in most cases the secured or unsecured overnight interbank rate - and that signals the policy stance. The target can be explicitly announced or implied by central bank operations - by tying it to a central bank instrument ${ }^{32}$ or facility, or by setting minimum or maximum bid rates in flexible-rate fixed-quantity open market auctions. ${ }^{33}$

In all cases, the policy rate constitutes a de facto commitment for the central bank to use its OMOs to ensure that the targeted market rate stays close to the target. All central banks have standing lending facilities, as these are essential for the functioning of the payment system. The rates on these are typically fixed and set at a margin above the policy rate, and thus act as a ceiling on short-term market rates in interest-rate-focused frameworks. Central banks are increasingly providing interest-earning deposit facilities, and an increasing number of central banks use the rate on these as the policy rate and operating target, while others set the deposit rate at a margin below the policy rate so that it acts as a floor for the short-term market rates. There are also important differences in how the OMOs are carried out, including with regard to the maturity of the instruments and whether they are issued at flexible-rate fixed-quantity auctions or at a fixed price with full allotment.

Based on how these factors are combined, three main configurations currently in use can be distinguished: ${ }^{34}$

\footnotetext{
${ }^{32}$ Examples of this include the fixed-quantity fixed-price OMOs at times used by, among others, the Bank of England (precrisis), the Swedish Riksbank, and the National Bank of Poland. See Bindseil and Nyborg (2007) for a discussion of the "overbidding" problem associated with such fixed-quantity fixed-rate systems.

${ }^{33}$ Examples of this include the ECB, whose pre-crisis policy rate was the minimum bid rate for its short-term open market lending operations (during the same period it would occasionally also conduct fixed-rate liquidity absorption operations at the policy rate).

${ }^{34}$ In principle, it is also possible to use a ceiling system where the rate on the central bank lending facility is the operating target and policy rate. This would be similar to the "classical system," where the central bank discount rate, or "Bank rate," was the main monetary policy tool (and with OMOs to "make the Bank rate effective" and keeping market rates close to the Bank rate; see Bindseil, 2004a, 2004b, and Tucker, 2004). Ceiling systems are not common anymore but may have some advantages when there is a risk of a run on the exchange rate.
} 
- The conventional flexible-rate fixed-quantity system, where the central bank uses flexiblerate fixed-quantity auctions of central bank or government paper to manage liquidity and to offset the impact of autonomous factors on banks' excess reserves in order to keep the targeted interbank rate in line with its announced, or implied, target. Some central banks also set (at the policy rate, implicitly or explicitly) a ceiling for liquidity absorption auctions or a floor for liquidity injection auctions, and may, through those maximum or minimum bid rates, signal its target rate.

- The floor system, where the interest rate on the central bank's overnight deposit facility, or the interest rate on excess reserves, is also the central bank policy rate and operating target, and OMOs are aimed at keeping the market sufficiently long so that short-term interbank market rates are at the floor.

- The fixed-at-the-policy-rate full-allotment system, where the central bank offers shortterm liquidity injecting or absorbing instruments at the policy rate and at the full amount demanded. ${ }^{35}$ The central bank would not announce any amount in advance, but banks would bid for quantities freely and the central bank would accept all bids. The policy rate would typically be positioned in the middle of a corridor set by the standing facilities.

Theory and experience indicate that each of these configurations has apparent advantages and disadvantages. None may be optimal in all circumstances, and countries have been adapting their frameworks as circumstances evolve. The three configurations differ regarding (1) their dependence on having a well-functioning non-segmented interbank market; (2) the need for an accurate central bank liquidity forecasting framework; (3) their reliance on the interbank market versus central bank facilities for intermediation of short-term funds; (4) the incentives they provide for short-term interbank trading; and (5) how well they anchor the lower end of the yield curve, facilitate market pricing of longer-term securities, and strengthen policy transmission along the yield curve when markets are not functioning well and central bank capacity is low. The structural liquidity situation, and whether the central bank is primarily injecting liquidity or mopping up excess liquidity, also has a bearing. The cost implications may typically be broadly similar, and thus should not be a central consideration in the choice of the operational framework. Instead, as discussed below, the choice should depend more on the functioning of the money market, the quality of the central bank liquidity forecasting, and consistency with the goal of facilitating financial market development.

\section{B. The Conventional Flexible-Price Fixed-Quantity System}

The conventional flexible-rate fixed-quantity system is the most demanding of the alternatives but has some advantages. There are two versions: with and without an interestearning deposit facility. Both require accurate short-term forecasts of the autonomous

\footnotetext{
${ }^{35}$ Examples include the liquidity-providing tenders used by the ECB since October 2008, the two-week certificates of deposit tenders used by the National Bank of Moldova, the two-week reverse repo tenders used by the Czech National Bank and the National Bank of Slovakia, and the two-week central bank bills and certificates of deposit used by the Hungarian Central Bank.
} 
liquidity factors, and solid central bank capacity to conduct frequent fine-tuned OMOs to offset the impact of these factors on excess reserves and keep the market in aggregate square and the targeted interbank rate in line with the policy rate. Both also rely on well-functioning and deep interbank markets, for: (1) banks to be able to predictably place surplus liquidity with, and obtain short-term funding from, each other at rates that are reasonably close to the policy rate; and (2) to ensure that shocks to banks' precautionary demand for reserve balances or credit risk factors do not cause undue volatility in rates. Both, however, also provide stronger incentives/needs for overnight interbank trading than do the other alternatives.

The version of this system with an interest-bearing deposit facility would generally be less demanding to operate than the version without. This is particularly so if the interest rate target is positioned in the middle of the corridor formed by the two standing facilities. As illustrated in Box 1 and more fully explained in Appendix II, in the corridor version, the central bank may simply aim its OMOs at keeping excess reserves constant, even when it wants to change the policy stance. The reason for this is that an equal change in the rates on the standing facilities would alter the cost to banks of ending the day short or long on reserves and thereby cause a parallel shift in the demand curve for reserve balances and in theory induce an equal change in the market rate. In contrast, under the version without an interest-earning deposit facility, changing the rate on the lending facility would only tilt the demand curve, and thus also require a change in excess reserves to achieve the targeted change in market rates. ${ }^{36}$ Moreover, positioning the target in the middle of the corridor so that the opportunity costs of being long or short are symmetric would make the market less vulnerable to shocks to banks' precautionary demand for reserve balances. ${ }^{37}$

\footnotetext{
${ }^{36}$ It can in practice be difficult to determine by how much excess reserves would have to change. The literature has struggled to find a relationship between interest rates and the quantity of reserves over shorter frequencies, as well as over longer horizons (see, among others, Borio (1997), Guthrie and Wright (2000), Thornton (2004), Carpenter and Demiralp (2006a, 2006b, 2008), and Friedman and Kuttner (2011) on this and the search for the "liquidity effect"). There are several factors that can explain this, including the ability of policy, via the standing facility rates, to tilt or shift the demand curve, and of reserve averaging to separate the timing of rate changes from the timing of changes in aggregate excess reserves, and thereby for expectations and announcements to shift rates ahead of changes in excess reserves. The empirical results suggest that demand for overnight reserve balances can be very interest-elastic within the reserve maintenance period under reserve averaging, but very interest-inelastic on the last day of the maintenance period and over the longer term.

${ }^{37}$ This relationship holds because these shocks would cause the demand curve to pivot at the midpoint of the corridor (Whitesell, 2006a).
} 


\section{Box 1. The Demand for Reserve Balances and the Role of Standing Facilities 1/}

Banks' demand for overnight reserve balances is closely linked to the volatility of interbank payment flows and the associated risk and cost of being short or long at the time of settlement closure. The central bank can influence interbank market interest rates by changing the supply of reserves, and thereby the probability of banks ending the day short or long, and/or by changing the rates on its standing facilities and thus the cost to banks of ending the day short or long and hence cause the reserve demand curve to shift, as illustrated in the figures below.

Changing the central bank lending rate alters the cost to banks of ending the day short and thereby tilts the demand curve and changes the interbank rate for a given supply of reserves.

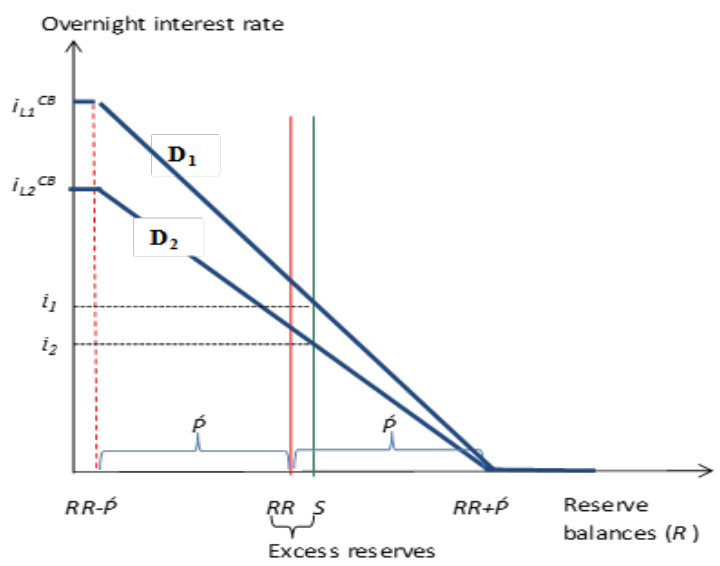

Introducing a deposit facility/start paying interest on excess reserves tilt and flatten the demand curve and cause the interbank rate to rise for a given supply of reserves.

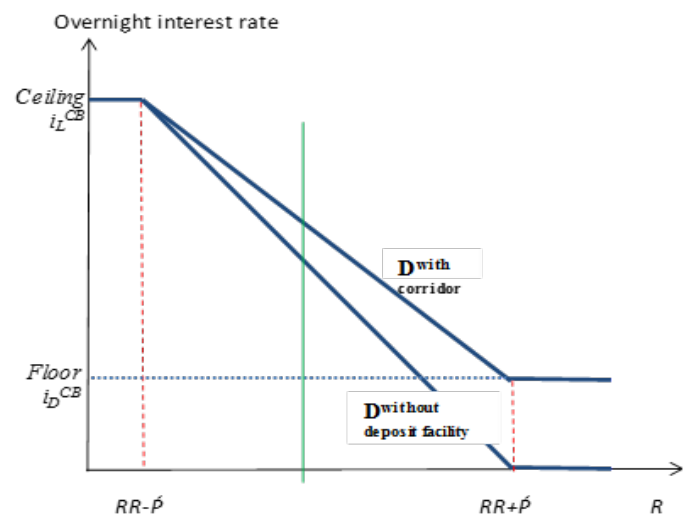

Reducing central bank lending and deposit facility rates shifts the demand schedule downward and reduces the interbank rate for a given supply of reserves.

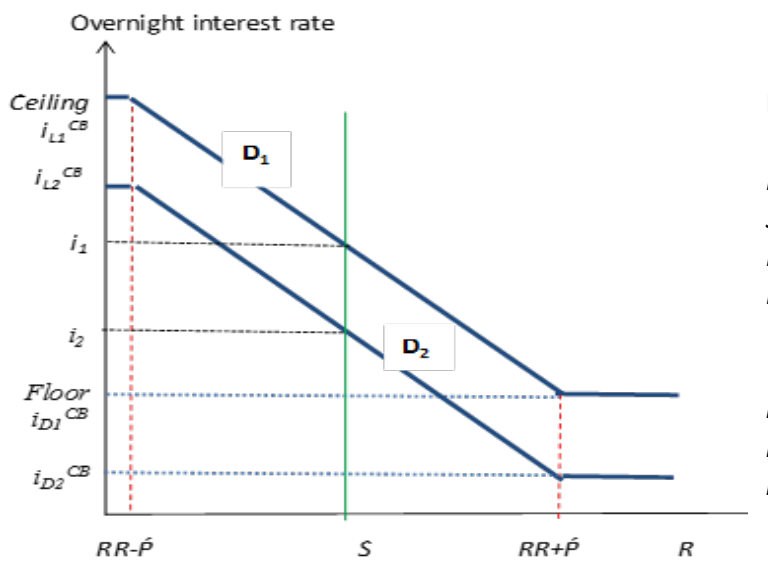

D Demand for reserves at the close of the Market

$R R \quad$ Required reserves

$S \quad$ Supply of reserves

$R \quad$ Reserve balances

$P \quad$ Stochastic after-close-of-market payment shock Uniformly distributed within the interval [-Ṕ,Ṕ]

$i \quad$ Interbank interest rate

$i_{L}{ }^{C B} \quad$ Central bank lending rate

$i_{D}^{C B} \quad$ Central bank deposit rate

1/ The figures are based on Ennis and Keister (2008), who provide a more in-depth discussion of this subject. See Appendix II for the underlying model as well as a complementary aggregate market model. 


\section{The Floor System}

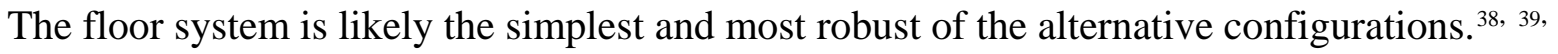
40 The central bank under a floor system needs to provide banks with sufficient excess reserves to ensure that the overnight market rate stays close to the policy rate. It could, however, increase the supply of liquidity further without risking pushing short-term interbank rates below the target, as the demand for reserves tends to become perfectly elastic once interest rates are close to the floor. Under a floor system the central bank can thus increase market rates by simply moving up the floor without having to drain any excess reserves. In effect, price and quantity become "decoupled" once excess reserves are

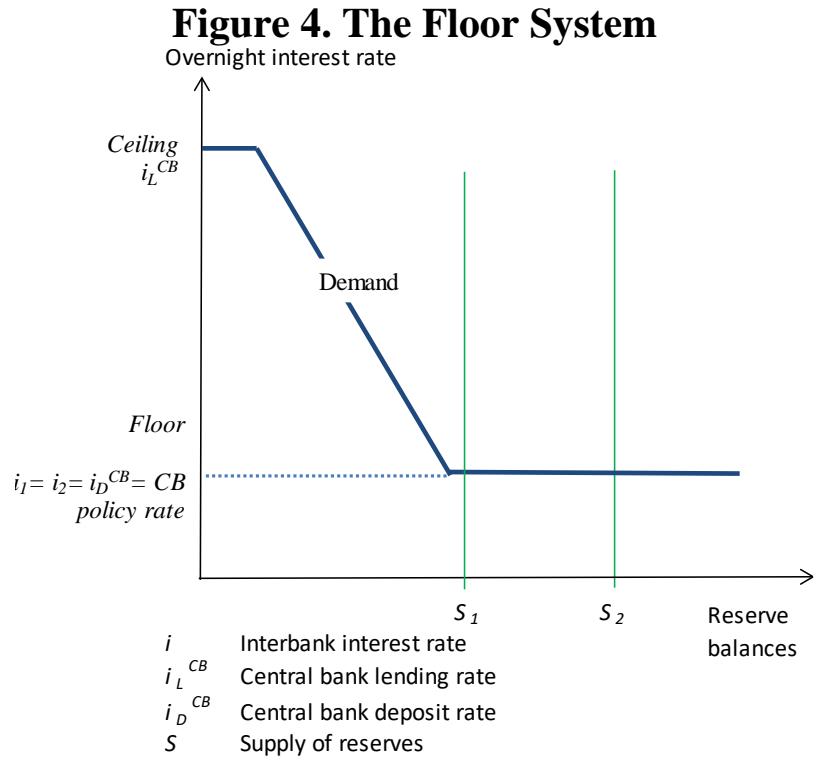
sufficiently large and rates are at the floor (Figure 4).

This decoupling of price and quantity under the floor system provides important advantages:

- It reduces the need for fine-tuned day-to-day liquidity operations to keep market rates aligned with the policy rate. The deposit facility will automatically drain the excess if more reserves than needed are provided. This may make the floor system particularly attractive for countries with less sophisticated liquidity forecasting frameworks and/or with large structural liquidity surpluses, which otherwise would have to be drained through active use of OMOs.

- It allows the central bank to control both interest rates and liquidity in the interbank market. In particular, it allows the central bank to provide the excess reserves needed to ensure that banks remain liquid, and not have to unwind payments or radically curtail lending in a crisis situation where the interbank market stops functioning properly

\footnotetext{
${ }^{38}$ Floor systems were, prior to the global financial crisis (GFC), common in a number of emerging market countries, including India, Russia, and most MENA countries. They were also used in a few advanced economy countries, notably Norway (since the mid-1990s) and New Zealand (since 2006) and have become more common in advanced economies following the use of unconventional monetary policy tools in response to the GFC, with the US, Canada, euro area, and the UK among others now operating de facto floor systems.

${ }^{39}$ See, among others, Goodfriend (2002), Keister, Martin, and McAndrews (2008), Berhardsen and Kloster (2010), Bowman, Gagnon, and Leahy (2010), Kashyap and Stein (2012), and Gagnon and Sacks (2014) for a further discussion of floor systems.

${ }^{40}$ When the structural liquidity position in the market is short, operating a floor system would require longerterm central bank lending (at the policy rate) to convert the structurally short position into a long one, which would require that banks hold sufficient high-quality collateral.
} 
without also impacting short-term interest rates. It also allows the central bank to provide emergency liquidity assistance to banks in trouble or inject liquidity to stabilize markets in the event of a financial crisis without the risk of the liquidity provided pushing down market interest rates and causing an unwarranted loosening of the policy stance.

- It makes market rates less vulnerable from shocks to banks' precautionary demand for reserve balances. This can be particularly advantageous in times of financial stress or poorly functioning or segmented interbank markets.

- It may help reduce banking costs and interest rate spreads. The abundance of costless and safe reserves earning close to the overnight interbank rate would reduce liquidity risk and thereby help reduce banking costs. ${ }^{41}$ Paying interest on excess reserves, moreover, would reduce the "reserve tax"; in fact, paying interest on both excess reserves and required reserves would eliminate it. Thus, the spread between lending and deposit rates should decrease. $^{42}$

The main argument raised against the floor system is that policy transmission could be weaker because: (1) the high level of excess reserves could reduce competition for bank deposits; and (2) floor systems provide less need for overnight interbank trading. However, these objections may not always be valid, and, in fact, transmission could be stronger under a floor system than under a conventional flexible-price fixed-quantity system when the central bank's liquidity management capacity is weak; financial markets are underdeveloped; or there are significant structural impediments to interbank trading such as high trading costs, significant counterparty risks, or a perception that interbank trading entail aiding its competitors. In particular:

- Banks should have the same incentive to mobilize deposits under a floor system as under a flexible-price fixed-quantity system, and transmission to retail deposit rates could be stronger. It should be profitable for banks under either system to attract additional deposits by bidding up deposit rates if the cost of doing so is lower than the marginal opportunity cost of obtaining or placing reserve balances. The opportunity cost for overnight funds/placement would be the interbank rate in a flexible-price fixed-quantity system with a functioning market and the interbank/deposit facility rate in the floor system. The strength of the transmission from changes in the policy rate to retail deposit rates therefore should be similar when the interbank market is functioning well and rates are properly aligned with the policy rate, but could be stronger under a floor system when that is not the case.

\footnotetext{
${ }^{41}$ It would also reduce banks' demand for central bank intraday, or daylight, credit.

42 It would also, as argued by Woodford (2001) and Goodfriend (2002), reduce banks' incentives for moving away from central bank reserve balances for payment services and for developing alternative electronic interbank settlement systems independent of the central bank, and help maintain central bank control over shortterm rates in an environment with no use of cash and the existence of competing interbank settlement systems.
} 
- By anchoring the short end of the yield curve, the floor system helps to develop the market for longer-term securities and thereby policy transmission along the yield curve. The central bank's deposit facility under the floor system provides the market with a riskfree investment option, earning the policy rate, on which to base the pricing of longerterm instruments even when the overnight interbank market is not functioning. This is arguably more important for the strength of the policy transmission than active overnight interbank money market trading in countries with underdeveloped financial markets. ${ }^{43}, 44$, 45, ${ }^{46}$ By ensuring a clear and relevant policy signal, the speed and strength of the transmission from changes in the policy rate to longer-term rates and to retail lending rates could in this case be stronger under a floor system than under a conventional flexible-price fixed-quantity system.

- By reducing short-term liquidity risk, the floor system may flatten the yield curve and encourage longer-term lending. The reduced interest rate volatility and reduced risk of being left short at the end of the day should reduce liquidity risk premiums and lower rates on longer-maturity securities. This, and the increased predictability of longer-term rates, should also reduce the incentive for liquidity hoarding and the risks associated with providing longer-term financing. It should also for that reason make longer-term rates more responsive to changes in the policy rate.

The tendency of floor systems to reduce interbank trading can be mitigated. Interbank trading volumes are primarily determined by the distribution of excess reserves, trading costs, and counterparty risks. ${ }^{47}$ Not supplying more reserves than what is strictly needed to keep rates at the floor would increase the likelihood that some banks would be short and actively seeking

\footnotetext{
${ }^{43}$ While an active overnight market might provide added support for policy transmission in developed markets, there are no empirical studies of this.

${ }^{44}$ With less need for overnight trading, banks can shift their scarce resources from managing short-term risk to managing longer-term risk and to the pricing and trading of longer-term instruments. The savings from such a shift can be substantial. Active management of overnight liquidity risks requires monitoring and accurately forecasting daily liquidity inflows and outflows, involving analysts, traders, back-office staff, managers and so on, to undertake the monitoring, forecasting, and trading (see also Bindseil and Nyborg, 2007).

${ }^{45}$ It is sometimes also argued that active interbank trading may help financial stability through increased incentives and scope for peer-monitoring of individual bank solvency risks. Others have argued, however, that because interbank trading is very short term, there is little focus on the long-term solvency of the borrowing bank (see Bernhardsen and Kloster, 2010). Moreover, active interbank markets did not prevent the recent financial crisis (much of which was bank sourced).

${ }^{46}$ The lack of established overnight interbank trading relationships may increase the risk of large spikes in interbank rates during times of less flush liquidity conditions, however, unless the corridor is kept sufficiently narrow.

${ }^{47}$ See Bindseil and Nyborg (2007) for a simple numerical example illustrating how trading volumes may depend more on the distribution of excess reserves among banks than the liquidity management framework.
} 
to borrow in the interbank market. ${ }^{48}$, 49 The risk that banks that are excessively long would not want to lend to the market because the reward of doing so would be too low can be mitigated by having a tiered rate structure for the deposit facility where deposits above a predetermined amount are remunerated at a lower rate. ${ }^{50}$

\section{The Fixed-Rate Full-Allotment System}

The fixed-at-the-policy-rate full-allotment system provides many of the benefits of the floor system. It may, however, come at the price of higher liquidity risks. Both are full allotment systems that provide for a degree of automatic alignment of interbank rates to the policy rate with less of a need for accurate short-term liquidity forecasting and fine-tuned OMOs. The maturity of the central bank instrument used, ${ }^{51}$ frequency of operations, ${ }^{52}$ and timing of the operations ${ }^{53}$ constitute the main areas of difference between these two systems. Moreover, while the floor system requires a structural liquidity surplus, the fixed-rate full-allotment system can be used regardless of whether the structural liquidity situation is long or short. ${ }^{54}$ By using a slightly longer-term instrument and less frequent operations, ${ }^{55}$ the fixed-rate fullallotment system would more often leave the market with an uneven distribution of excess reserves, which could increase the need and the incentive for interbank trading. However, it would also increase short-term liquidity risk and require a better functioning interbank market for banks to be able to manage those risks to the same degree as under a floor system.

\footnotetext{
48 That is, in Figure 4, by keeping the supply of reserves close to $S_{1}$ and not $S_{s}$.

49 This may also be beneficial in the event of an attack on the exchange rate, as it could facilitate an automatic increase in short-term rates without having to increase the policy rate. Allowing short-term rates to temporarily deviate from the policy rate in exceptional cases, such as an attack on the exchange rate, may help insulate longer-term rates and reduce real economy costs.

${ }^{50}$ For this reason, New Zealand shifted from a conventional floor system to a tiered rate structure in 2007, and Norway likewise did so 2011. See also Whitesell (2006b) for a theoretical model of this truncated floor system.

${ }^{51}$ Overnight in the case of a floor system and typically one or two weeks in the case of the fixed-rate fullallotment system with reserve averaging.

52 Daily in the case of floor systems and potentially less frequently under the fixed-rate full-allotment system, if reserve averaging is allowed. The optimal frequency would depend on the length of the reserve requirement maintenance period (MP) and the functioning of the interbank market. There should be at least two auctions during the MP, with one taking place on the last day of MP.

${ }^{53}$ Access to the deposit facility could be throughout the day or at the end of the trading day in the case of floor systems, while the timing of the auctions could be at the beginning, the middle, or the end of the trading day in the case of the fixed-rate full-allotment system.

${ }^{54}$ It should not be close to zero, but either relatively long or relatively short, to ensure that the central bank is either consistently withdrawing or injecting excess reserves through its fix-rate full-allotment operations. Occasional longer-term structural operations can be used to ensure that the structural position stays sufficiently long or short.

${ }^{55}$ Using longer term instruments and less-than-daily operations would require allowing required reserves to be met on an average basis over a sufficiently long reserve maintenance period, though.
} 
Both floor and fixed-rate full-allotment systems can work with poorly functioning interbank markets. In both systems, banks would be able to predictably place surplus liquidity with the central bank at rates that are reasonably stable and persistent. This should help ensure that the policy rate is relevant for banks' liquidity management, even when there is no wellfunctioning interbank market.

The conventional flexible-price fixed-quantity system may perform better than the fixed-rate full-allotment system when the central bank's short-term liquidity forecasts are accurate. The fixed-rate full-allotment system is equivalent to letting the individual banks not only do the forecasting of their near-term liquidity needs and inflows and outflows, but of the aggregate autonomous liquidity flows as well. The central bank should generally have a comparative advantage over the market in forecasting these aggregate flows, since they reflect financial transactions affecting the balance sheet of the central bank. There is some evidence that banks tend to overbid for liquidity under the fixed-rate full-allotment system, and for postallotment interbank rates to dip below the tender rate. ${ }^{56,57}$

\section{E. The Optimal Width of the Interest Rate Corridor ${ }^{58}$}

Setting the interest rate corridor too wide may hamper market development and the transmission of policy signals and could lead to reserve hoarding. A wide corridor discourages reserve intermediation via the central bank and thus creates incentives for banks to deal among themselves in the overnight interbank market, but it can also result in relatively high day-to-day interest rate volatility. This high interest rate volatility, moreover, would complicate banks' liquidity management, and could discourage trading by making it riskier to rely on the market for fine tuning their reserve holdings. Banks in LLMICs with opaque operational frameworks and high liquidity and counterparty credit risks tend to selfinsure by hoarding liquid assets (excess reserves and other deposits at the central bank and short-maturity securities) and by predominantly lending short term. ${ }^{59}$

Setting the corridor on the narrow side, which could reduce the incentives for overnight interbank trading, may be of less concern. As discussed above, the better anchoring of shortterm rates should help in developing the market for longer-term financial instruments, and thereby augment transmission along the yield curve, which is likely more important for the

\footnotetext{
${ }^{56}$ See Bindseil (2011) on this.

${ }^{57}$ Providing the market with information, including forecasts, about forthcoming aggregate autonomous liquidity flows as well as planned central bank operations to counter them, as needed, could help reduces but not eliminate this (market coordination) problem.

58 See also Gray and others (2013) and Bindseil and Jabłecki (2011a) for a discussion of this subject.

59 The theoretical model presented in Bindseil and Jabłecki (2011b) suggests that when interbank markets break down because of (perceived) elevated counterparty credit risks, a narrower corridor would lower lending, increase intermediation among households and corporations, reduce interbank trading, and increase the use of the standing facilities.
} 
strength of policy transmission than active overnight trading in countries with underdeveloped financial markets.

Table 1. Interest Rate Corridor Width in Selected Countries

\begin{tabular}{|c|c|c|}
\hline & 2008 & 2013 \\
\hline $\begin{array}{l}\text { 50bp and } \\
\text { less }\end{array}$ & $\begin{array}{l}\text { Australia, Canada, Chile, Malaysia, } \\
\text { New Zealand }\end{array}$ & $\begin{array}{l}\text { Australia, Canada, Chile, Colombia, Czech } \\
\text { Republic, Israel, Kazakhstan, Malaysia, New Zealand }\end{array}$ \\
\hline 75bp & & Jordan, United Kingdom \\
\hline 100-149bp & $\begin{array}{l}\text { Norway, Singapore, South Africa, } \\
\text { Thailand }\end{array}$ & Afghanistan, Egypt, Fiji, Norway, Thailand, Tunisia \\
\hline 150-199bp & Afghanistan, Iceland, Sweden & Euro area, Sweden, Peru \\
\hline 200bp & $\begin{array}{l}\text { Czech Republic, Hungary, } \\
\text { Israel, Papua New Guinea, United } \\
\text { Kingdom }\end{array}$ & $\begin{array}{l}\text { Argentina, Colombia, DRC, Costa Rica, Dominican } \\
\text { Republic, Guatemala, Hungary, Indonesia, Korea, } \\
\text { Morocco, South Africa }\end{array}$ \\
\hline $\begin{array}{l}\text { More than } \\
\text { 200bp }\end{array}$ & $\begin{array}{l}\text { Albania, Cape } \\
\text { Verde, Croatia, Dominican } \\
\text { Republic, Indonesia, Poland, } \\
\text { Romania, Serbia }\end{array}$ & $\begin{array}{l}\text { Albania, Bhutan, Brazil, Croatia, Honduras, Iraq, } \\
\text { Mauritius, Moldova, Mongolia, Mozambique, Nigeria, } \\
\text { Romania, Rwanda, Serbia }\end{array}$ \\
\hline
\end{tabular}

Source: IMF ISMP database.

High interest rate levels and the existence of other volatility absorption mechanisms could, however, justify having a wider corridor. Requiring banks to only meet reserve requirements on average over a sufficiently long maintenance period and not daily can help the market absorb liquidity shocks. High interest rate levels may also justify a somewhat wider corridor, including because policy rate adjustments tend to be larger in absolute terms, the higher the interest rate level. ${ }^{60}$

\section{F. Implications for Central Bank Costs}

Managing liquidity so that short-term rates are stable and well aligned with the policy rate can be costly and therefor put the central bank in a difficult political spot when structural liquidity surpluses are large, but failure to do so could carry even higher costs if monetary policy objectives are not achieved. Most of the structural surplus liquidity would have to be drained through OMOs under the conventional flexible-rate fixed-quantity and the fixed-rate full-allotment systems or be remunerated at the deposit rate under the floor system. The associated interest cost can be high. Therefore, many central banks, at least during the transition to a new framework, may choose to rely on un-remunerated reserve requirements - which constitute a tax on the banking system and widen retail interest rate spreads - to reduce the structural liquidity surplus. Failing to do either would result in below-

60 To minimize potential arbitrage activity when policy rate changes are expected, with reserve averaging, the corridor should be wider than the usual, or potential, change in the policy rate. Otherwise, banks could use the standing facilities to lend (borrow) in large volumes before the rate decision and borrow (lend) after the rate decision and still meet the reserve requirements. Aligning the maintenance period with the timing of policy rate decisions would help in preventing such round-tripping. 
target market rates and a looser-than-intended policy stance. Attempting to save costs by only periodically draining excess liquidity could be equally damaging to the economy and central bank credibility. It would result in high liquidity risk and volatile interest rates, high risk premiums and a steeper yield curve, and weak policy transmission.

The cost difference between the alternative operating frameworks discussed may be small, and much smaller than commonly assumed. While an interest-earning deposit facility does involve paying interest on banks' precautionary demand for excess reserves - that is, the excess reserves consistent with keeping market rates at target- there are several mitigating factors: ${ }^{61}$

- Precautionary demand for overnight balances can be very low and the use of the deposit facility can be close to zero in a well-managed mid-corridor system. Theory suggests that the precautionary demand should be zero when the target is set at the middle of the corridor and the distribution of payment shocks is symmetric with a zero mean. In that case, the central bank's target for excess reserves should be zero, or close to zero. ${ }^{62,63}$

- The cost of paying interest on excess reserves could in some cases be partly or fully offset by reduced OMO costs under a floor system. In the case of a large structural surplus, the alternative to remunerating excess reserves at the policy rate would be to mop most of them up using longer-maturity OMO instruments. There should be a small but positive difference between the interest rate on these instruments and the interest rate on the deposit facility, as long as the term premium is positive. ${ }^{64}$ Similarly, in the case of a structural liquidity deficit, the funds placed in the deposit facility would first have to be injected trough central bank term-lending or OMOs. In either case, their maturity would typically be longer than overnight and carry a higher interest rate. Thus, compared to a mid-corridor system, or a flexible-price fixed-quantity system without a deposit facility

\footnotetext{
${ }^{61}$ It could in principle be possible to only remunerate excess reserves above a certain minimum if precautionary demand is high.

${ }^{62}$ Bank of Canada operated with a zero target for a short period, and subsequently with a small positive target for overnight reserve balances (Howard, 1998, with subsequent updates). Similarly, the Reserve Bank of New Zealand for a time operated with an overnight reserve target of only \$NZ20 million (Frazer, 2005) and Bank of England with an overnight reserve target of only £45 million (Tucker, 2004).

${ }^{63}$ There will, however, in practice be a small amount of excess reserves even in the best functioning midcorridor system, as banks that are long may not find it profitable to lend smaller amounts to banks that are short because of fixed administrative costs. For example, even if an overnight trade yields a gain of 200bp, the bank will only earn US $\$ 5.5$ on a US $\$ 100,000$ deal, which would likely not cover the fixed settlement costs.

${ }^{64}$ In New Zealand, the spread between the policy rate and the 30-day bank bill averaged 17bps in 2010-14 when it operated a two-tier floor system. There can also be a persistent small positive spread between the central bank deposit rate and the overnight interbank rate under a floor system. In the case of Norway, interbank rates were on average around 20-30 bps above the deposit rate in 2010-2011 when Norway operated a conventional floor system.
} 
that is well managed and where excess reserves would be low, moving to a floor system could in fact result in lower central bank costs. ${ }^{65}$

\section{SUMMARY AND CONCLUSIONS}

Improving the operational framework should be a central focus in countries striving to modernize their monetary policy framework. Shortcomings in the operational framework and weak liquidity management are in many cases the major obstacles to effective monetary policy in LLMICs. While clarity on the policy objective, comprehensive forward-looking policy analysis to determine the appropriate policy stance to achieve the policy objective, and clear communication are essential elements of any effective monetary policy framework, a well-functioning operational framework is needed to ensure that policy objectives are achieved reliably and efficiently. Policy operations that cause significant liquidity risk and high interest rate volatility, large and systematic differences between interbank rates and the central bank policy rate, and thus between the stated and the de facto policy stance, all risk undermining policy transmission and central bank credibility.

The paper has argued that stabilizing short-term interest rates on a day-to-day basis has significant advantages, and thus that short-term interest rates, not reserve money, in most cases should be the daily operating target, including for countries relying on a money targeting strategy. The main reason is that policy operations work primarily through their impact on interest rates, liquidity risk, explicit and implicit yields, the exchange rate, and expectations, even in countries in which financial markets are not yet fully developed. Policy transmission to longer-term rates and deposit and lending rates should be stronger when monetary operations ensure reasonably stable and predictable short-term rates.

An operational framework that ensures reasonably stable and predictable short-term interest rates can be compatible with retaining a role for monetary aggregates. Monetary aggregates can be used as intermediate targets, or information variables, to guide the setting of the interest rate target. This would be similar to how advanced countries used a short-term interest rate as the operating target when they formally followed a MT policy strategy. Countries seeking to retain some operational role for reserve money targets and focus operations on keeping quantities on a path consistent with these targets, can reduce shortterm interest rate volatility by using a path for total reserves derived from their term reserve money targets as the operating target for their daily liquidity management. Such a quantitybased operational framework can be combined with a firm interest rate corridor formed by central bank standing facilities to cap interest rate volatility but would not be compatible with having a central bank policy rate to signal the policy stance.

Furthermore, the optimal configuration of a fully interest-rate-based operational framework would likely depend on the country-specific circumstances. The alternatives discussed differ

${ }^{65}$ See Goodfriend (2002) for an early discussion of this in the case of the US, and Keister, Martin, and McAndrews (2015) for a fuller theoretical discussion. 
regarding: (1) their dependence on having in place a well-functioning interbank market; (2) the need for having a highly accurate central bank liquidity forecasting framework; (3) their reliance on the interbank market versus central bank facilities for intermediation of shortterm funds; (4) the incentives they provide for short-term interbank trading; and (5) how well they anchor the lower end of the yield curve and facilitate policy transmission along the yield curve when markets are not well functioning.

While considerable judgment appears to be needed in selecting an operational framework in any given case, the following general observations may help to inform the decision:

- The conventional flexible-rate fixed-quantity system is the most demanding of the alternatives. It requires accurate short-term forecasts of the autonomous liquidity factors and solid central bank capacity to conduct frequent fine-tuned OMOs in order to keep the market in aggregate square and interbank rates in line with the policy rate. It also requires well-functioning and deep interbank markets. However, it also provides stronger incentives for active overnight interbank market trading.

- Floor and fixed-rate full-allotment systems are simpler and more robust. They do not require well-functioning interbank markets - the floor system can work even without a functioning overnight interbank market—or highly accurate short-term liquidity forecasting frameworks. While the floor system may provide fewer incentives, or less of a need, for overnight interbank trading, policy transmission could in fact be stronger than under the conventional system when the central bank's liquidity management capacity is weak, financial markets are underdeveloped, or there are significant structural impediments to interbank trading. The result, more effective anchoring of the short end of the yield curve, should help in developing the market for longer-term securities and thereby strengthen transmission along the yield curve.

Further, and more empirical work, on the strength of transmission under alternative configurations of the operating framework and how it might depend on the country circumstances is needed. Views differ on the extent to which overnight interbank activity matter for policy transmission and for development of capital and longer-term security markets in countries with developed as well as underdeveloped financial markets. Views also differ on the appropriate size of central banks' balance sheet and whether transmission might be stronger when the central bank operate from a structurally short position and thus are injecting reserves on a daily basis instead of operating from a structurally long position as under a floor system. Views also differ on the benefits of reserve averaging and the associated use of less frequent OMOs with longer maturity instruments that reserve averaging offers. 


\section{APPENDiX I. INTEREST RATE VOLATILITY AND ALIGNMENT IN SELECTED CounTRIES}

Figure 1. Policy and Overnight Interbank Rates in Selected Low- and Middle-Income Countries
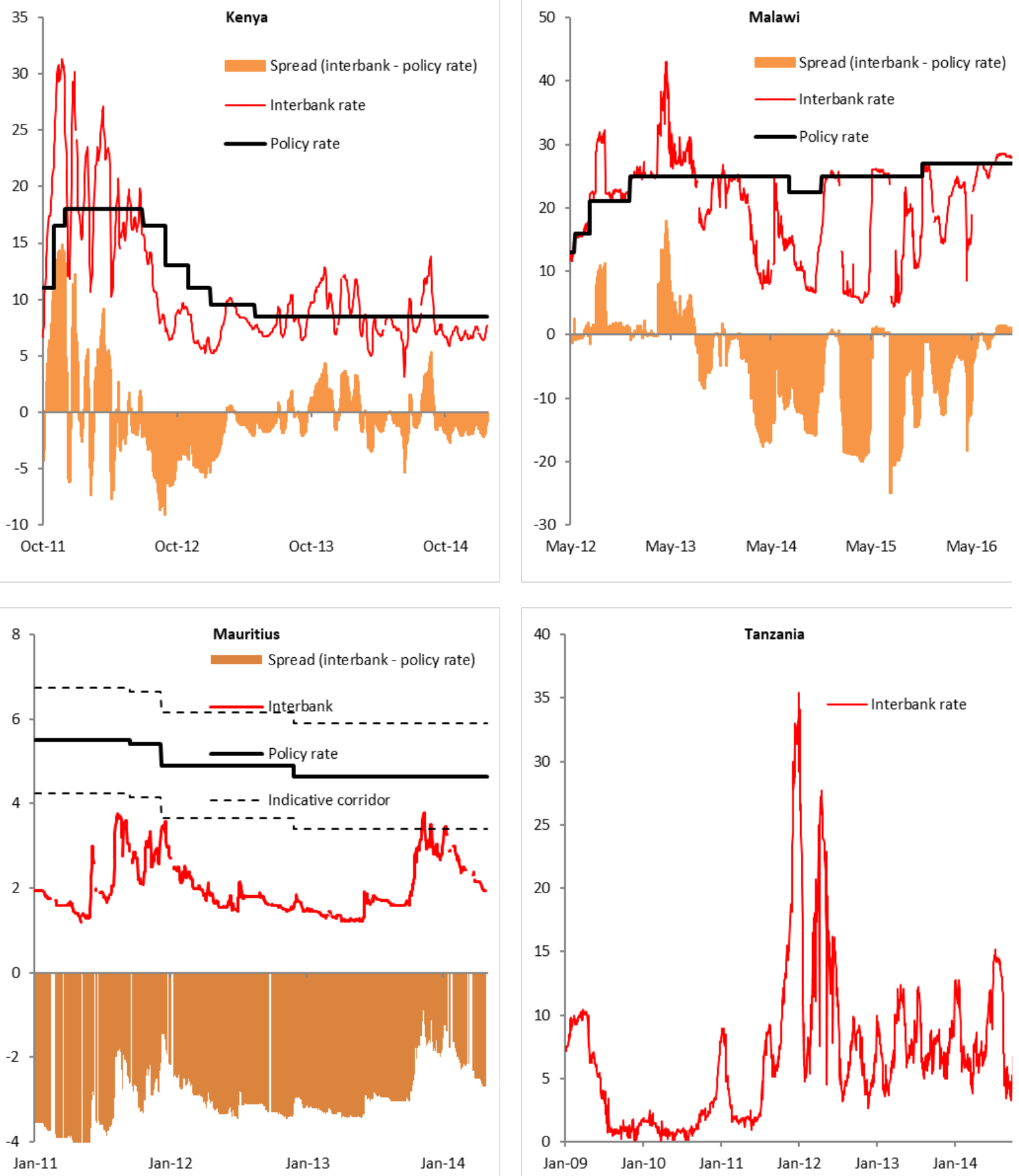

Sources: Central banks of Kenya, Malawi, Mauritius, and Tanzania. 
Figure 1. Policy and Overnight Interbank Rates in Selected Low- and Middle-Income Countries (Continued)
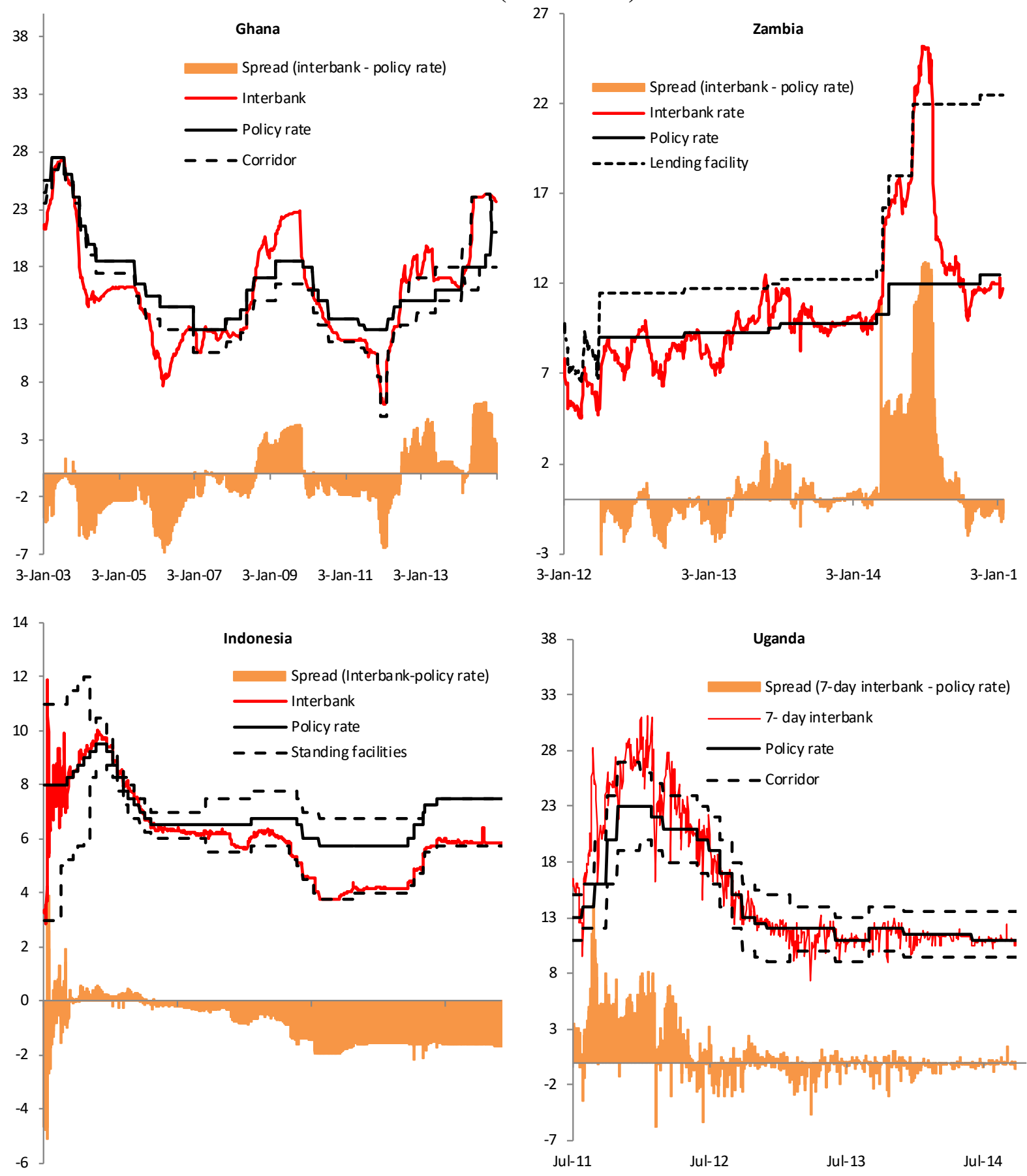

31-Dec-07

31-Dec-09

31-Dec-11

31-Dec-13

Jul-11

Jul-12

Jul-13

Jul-14

Sources: Central banks of Ghana, Indonesia, Uganda, and Zambia. 
Figure 2. Policy and Overnight Interbank Rates in Selected Advanced Economy Countries
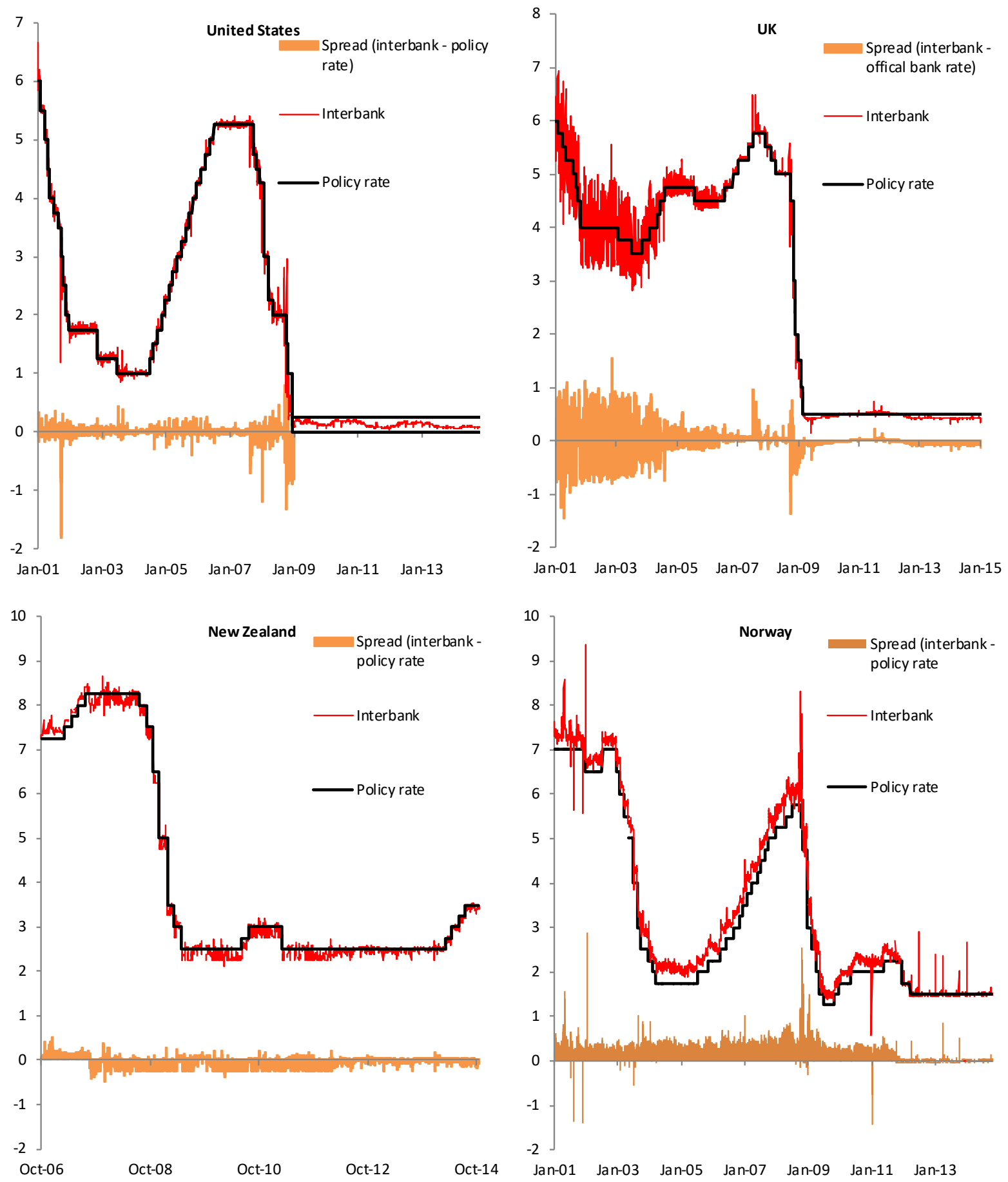

Sources: Central banks of New Zealand, and Norway, the United States, and the United Kingdom. 
Figure 2. Policy and Overnight Rates in Selected Advanced Economy Countries (Continued)
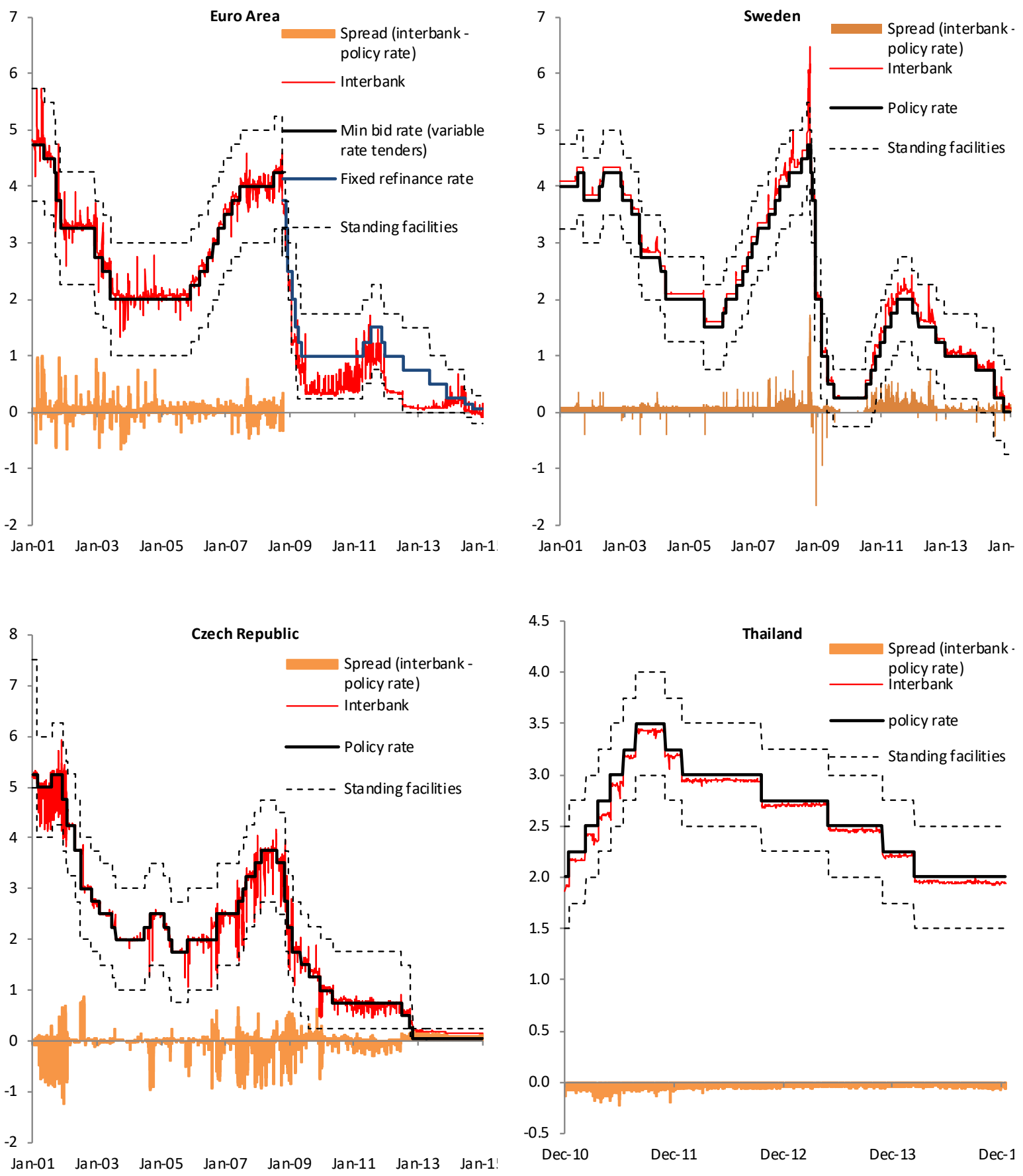

Sources: Central banks of the Czech Republic, the Euro Area, Sweden, and Thailand. 


\section{APPENDIX II. DEMAND FOR RESERVES BALANCES, UNCERTAINTY, AND THE ROLE OF STANDING FACILITIES}

\section{A. Introduction}

Commercial banks use their deposits at the central bank - their reserve balances - for interbank payments. They typically receive, and make, a number of interbank payments each day. Most of these may be for interbank settlements of transactions they carry out on behalf of their customers. The net aggregate of these interbank transactions would of course be zero at any point in time, as one bank's interbank payment outflow is another bank's payment inflow. However, each individual bank risks during the day either becoming short of reserve balances and having to borrow from the central bank, or other banks in the interbank market, in order to settle its payment obligations in the (real time gross) settlement system or ending up with more reserve balances than it would like and thus may want to lend to other banks.

Moreover, because of factors such as operational glitches, information or market failure, and late-in-the-day payment shocks, individual banks also risk ending the day with either a short position or a long position with (excess) overnight balances at the central bank. Either can be costly. A bank that ends the day short would have to access the central bank's standing lending facility in order to avoid failing an interbank payment or breaching the reserve requirement, while a bank that ends the day long would forgo the interest it could have earned by lending those funds in the market. When determining how much reserve balance to hold, whether and how to bid for a central bank OMO or government security, and how much to lend in the market, a profit maximizing commercial bank would have to balance the risk and cost of ending the day short against the risk and cost of ending the day long. This is the essence of the model for an individual bank's demand for excess reserves discussed in more detail in Section B below.

Banks in addition are faced with shocks to the banking system's aggregate reserve balance position. In addition to using their reserve balances to transact with each other, they use them to transact with the central bank and, if government has an account with the central bank, with the government. The total stock of reserve balances held by the banking system would, for example, decline when banks use their deposits at the central bank to buy local or foreign currency, or securities from the central bank, or to execute a tax payment on behalf of a customer. As a result, since there is a risk that these "autonomous" transactions are not fully offset by same day opposite central bank OMOs, the system in aggregate can risk ending the day: (1) short of reserves, and with some banks having to borrow from the central bank to close out their end-of-day position; or (2) long, and with some banks having to hold overnight un-remunerated excess reserves, or have funds placed in the central bank deposit facility that earn less than the interbank market rate. In addition to considering the risks to their individual reserve positions, banks would also have to factor in this risk of the market in aggregate ending the day short or long when they earlier in the day decide on how to bid for a central bank OMO or government security, and how much to lend in the market. This is the essence of the aggregate model of the interbank market and the interbank interest rate discussed in Section C below. The two models complement each other and result in the same 
fundamental relationships between reserves, the interbank interest rate, the standing facility rates, and payment shock risks.

\section{B. The Individual Bank Model ${ }^{1}$}

Assume that banks are risk-neutral and profit maximizing. Moreover, assume that banks during the day can borrow and lend reserves in a competitive interbank market at a known fixed interest rate. The central bank controls the total stock of reserves through its OMOs. Moreover, assume that after the interbank market has closed, each bank experiences a stochastic positive or negative payment shock that affects its end-of-day reserve balance position, but not the aggregate position. The value of the end-of-day

Figure 1. Reserves, and Banks’ Daily Liquidity Management Challenge

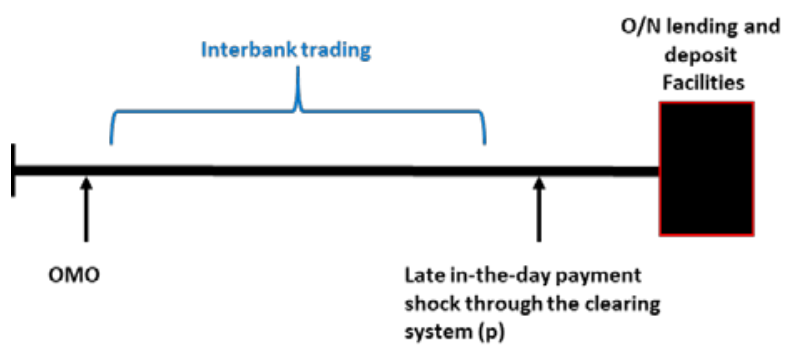
payment shock is not known while the interbank market is open. Finally, assume that each bank must meet a reserve requirement at the end of each day (which could be zero), and that they have full access to a central bank collateralized standing lending facility at a fixed interest rate and that there is no stigma or other costs attached to accessing it. The central bank may, or may not, pay interest on excess reserves/offer an interest earning standing deposit facility. Let:

$R \quad$ Stock of reserves after the close of the market and before the after-market payment shock.

$S \quad$ Supply of reserves.

$P \quad$ Stochastic end-of-day after-market-closure payment shock.

$f(P) \quad$ The probability density-function for the late-day payment shock. The probabilities are assumed to be uniformly distributed within the interval $[-P, P ́]$ in the simplified linear case depicted in Box 1 and Figure 4, but may more generally be non-uniform and bell-shaped.

$R R \quad$ End-of-day required reserve position. $R R \geq 0$.

$i \quad$ Overnight interbank interest rate. Assumed to be known and constant throughout the day.

$i_{L}{ }^{C B} \quad$ Central bank overnight lending rate.

$i_{D}{ }^{C B} \quad$ Central bank overnight deposit rate.

A risk-neutral profit maximizing bank under these assumptions would aim at an end-of-day reserve position $R$ that balances the opportunity cost of holding it against the risk of having to access the central bank's overnight lending facility to make up for any shortfall.

\footnotetext{
${ }^{1}$ This presentation of the model is based on the May 5, 2008, version of Ennis and Keister (2008). The model is in the tradition of models for banks' demand for reserve balances under payment uncertainty, based on the seminal contribution by Poole (1968). See also, among others, Henckel, Inze, and Kovanen (1999), Woodford (2001), Bartolini, Bertola, and Prati (2001, 2002), Gaspar, Perez-Quiros, and Rodriguez-Mendizábal (2004), Whitesell (2006a), and Ennis and Weinberg (2007).
} 


\section{The benchmark case without an interest-earning deposit facility}

The opportunity cost of holding reserves overnight instead of lending them to another bank would in this case be equal to $i \cdot R$ and the cost of having to access the lending facility in the case of a payment outflow of size $P \geq(R-R R)$ would be $i_{l}{ }^{C B}$. $(P-(R-R R)$. Thus, the bank would target the end-of-day stock of reserves that would minimize:

$$
i \cdot R+\int_{R-R R}^{\dot{P}} i_{\mathrm{L}}^{C B} \cdot(P-(R-R R)) \cdot f(P) d P
$$

Which would give the following first-order condition:

$$
i-i_{L}^{C B} \cdot \int_{R-R R}^{\dot{P}} f(P) d P=0<=>i=i_{L}^{C B} \cdot(1-F(R-R R))^{2}
$$

That is, the optimal stock of reserves would equate the opportunity cost of holding one more unit of reserves with the marginal change in the expected cost of being short. The expected cost of being short is equal to the product of the interest cost the bank has to pay if it is short and the probability of becoming short, which again depends on the stock of reserves the bank holds and the likelihood of a sufficiently large payment shock.

It follows that an increase in the central bank's lending rate, everything else equal, would cause an increase in the interbank market rate and steepen the slope of the demand curve. The increase in the interbank rate would be less than the increase in the lending facility rate, though.

It also follows that with a symmetric zero-mean payment shock probability density function, it would be optimal to aim at ending the day short and having to regularly access the central bank lending facility if $i>\frac{1}{2} i_{L}^{C B}$, and that it would be optimal to aim at ending the day long if $i<\frac{1}{2} i_{L}^{C B}$.

The slope of the demand curve is given by:

$$
\frac{d i}{d R}=-i_{L}^{C B} \cdot f(R-R R)
$$

This benchmark case without an interest earning deposit facility is illustrated in Figure 2. Market rates for secured interbank borrowing cannot be above the lending facility rate, as banks that are short but with the required collateral would then instead borrow from the facility to meet both the reserve requirement and cover the payment outflow. They would be indifferent about holding any amount between zero and $R R-P$ when rates are equal to the central bank lending rate, as, in such a situation they would have to borrow from the lending facility, even in the case of a maximum end-of-day inflow $(-\dot{P})$. The alternative of borrowing more from (lend less to) the market to reduce the risk of having to access the lending facility

\footnotetext{
${ }^{2}$ Where $F(R-R R)$ is the cumulative distribution function defined as $\int_{-P}^{R-R R} f(P) d P$, and $\int_{-P}^{P} f(P) d P=1$.
} 
would deliver the same net interest rate expense (lost earning). Similarly, if market rates are close to zero, the opportunity cost of holding excess reserves would be low and banks would want to hold enough reserves to be virtually certain that they will not risk having to access the lending facility even in the case of a maximum end-of-day payment outflow $(\dot{P})$. That is, they would like $R>R R+P$. The demand curve will be linearly downward sloping between these two points under a uniform distribution of the payment shock, as in the left-hand panel of Figure 2, and curved as in the right-hand panel of Figure 1 if the payment shocks follow a bell-shaped distribution.

\section{Figure 2. The Market for Reserves: Benchmark Case without a Deposit Facility}
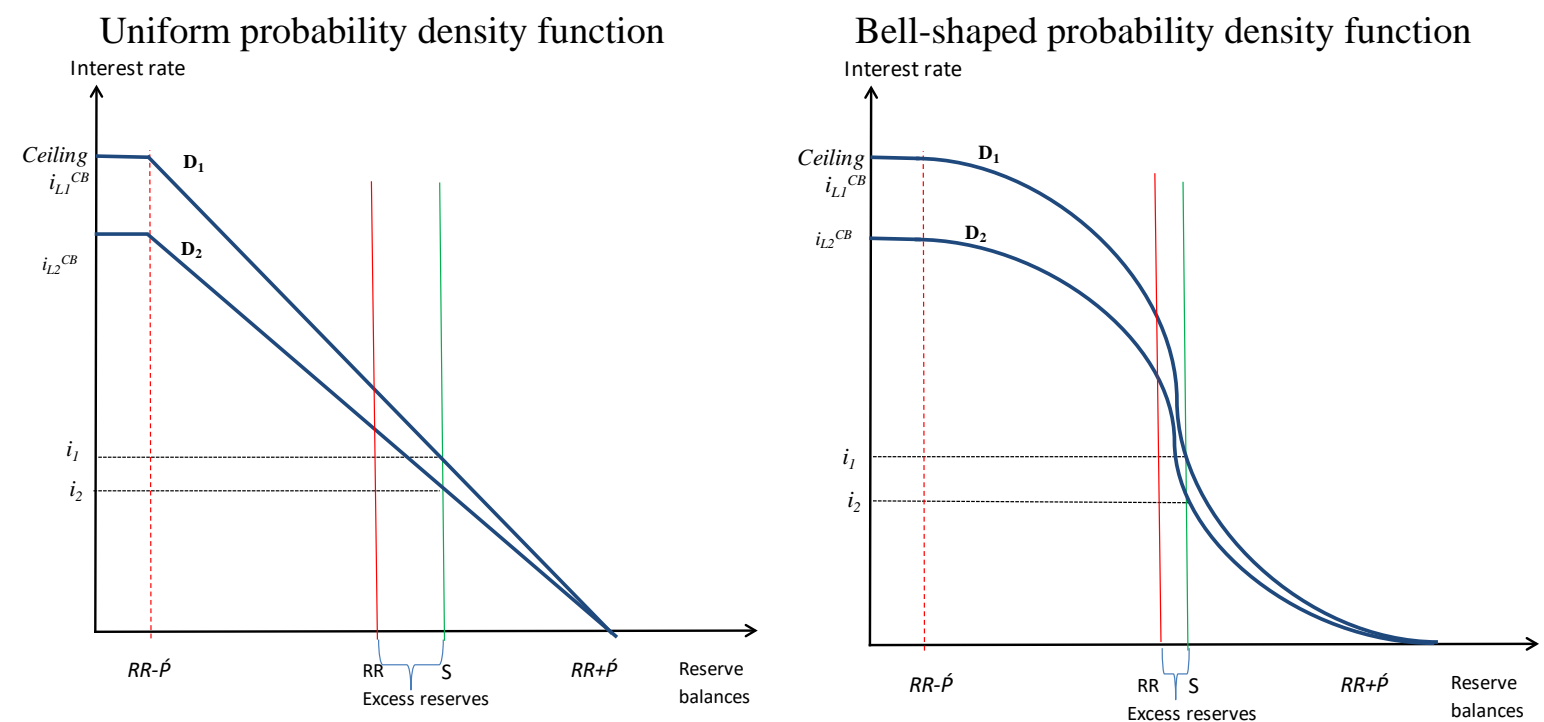

\section{The benchmark case with an interest earning deposit facility}

The opportunity cost of holding reserves would change with an interest earning deposit facility in place. The interest they could have earned by lending all reserves at the market rate would still be equal to $i \cdot R$, but in this case they would also be earning $i_{D}^{C B} \cdot((R-R R)-P)$ on the reserves they are holding in the deposit facility in the case of a payment outflow if size $P \leq$ $(R-R R) .{ }^{3}$ The bank would thus target the end-of-day stock of reserves that minimizes:

$i \cdot R-\int_{-\dot{P}}^{R-R R} i_{D}^{C B} \cdot((R-R R)-P) \cdot f(P) d P+\int_{R-R R}^{\dot{P}} i_{L}^{C B} \cdot(P-(R-R R)) \cdot f(P) d P$

Which would give the following first-order condition:

$i=i_{L}^{C B} \cdot(1-F(R-R R))+i_{D}^{C B} \cdot F(R-R R)=i_{D}^{C B}+\left(i_{L}^{C B}-i_{D}^{C B}\right) \cdot(1-F(R-R R))$

\footnotetext{
3 This formulation implies that the central bank does not pay interest on required reserves. This, however, is not a material assumption regarding the banks' optimal reserve holdings, as changing this assumption would just require adding $i_{D}{ }^{C B} \cdot R R$ to equation 4 .
} 
That is, the optimal stock of reserves would equate the opportunity cost of holding one more unit of reserves with the marginal change in the expected cost of being short, plus the marginal change in expected interest earned on deposits in the deposit facility if long. Put differently, they would aim at the stock of reserves that equates the interbank market rate with the weighted average of the standing facility rates, with the probability of being short $(1-F(R-R R))$ or long $(F(R-R R))$ as weights.

It follows that an equal increase in both the central bank's lending deposit and rates would cause an equal increase in the interbank market rate, with unchanged reserve holdings. It also follows that the optimal stock of reserves, when rates are at the middle of the corridor, would be equal to the required reserves - that is, banks' optimal stock of excess reserves would be zero-if the payment shock probability density function is symmetric with a zero mean. Similarly, it follows that it would be optimal to aim at being short if rates are above the middle of the corridor and aim at being long if rates are below the middle of the corridor. Finally, the model solution implies that while banks' demand for (excess) reserves is a function of the location of the interbank rate relative to the standing facility rates, it is not on the absolute level of interest rates.

The slope of the demand curve in this case is given by:

$$
\frac{d i}{d R}=-\left(i_{L}^{C B}-i_{D}^{C B}\right) \cdot \mathrm{f}(R-R R)
$$

Which implies that a narrowing of the interest rate corridor, or reduced spread between the central bank lending and deposit rates, would flatten the demand curve and reduce the volatility of the interbank rate even when banks are not accessing either of the two facilities.

This basic benchmark case with an interest-earning deposit facility is illustrated in Figure 3. In this case, when market rates are close to the rate the central bank pays on its deposit facility, the opportunity cost of holding reserves would be low and banks would want to hold enough precautionary reserves to be virtually certain that they will not risk having to access the lending facility even in the case of a maximum end-of-day payment outflow. That is, they would like R > RR+ Ṕ. Again, the demand curve will be linearly downward sloping between these two points under a uniform distribution of the payment shock, and changes in the rates on the central bank's standing lending and deposit facilities would shift the demand curve. 
Figure 3. The Market for Reserves: Benchmark Case with a Deposit Facility
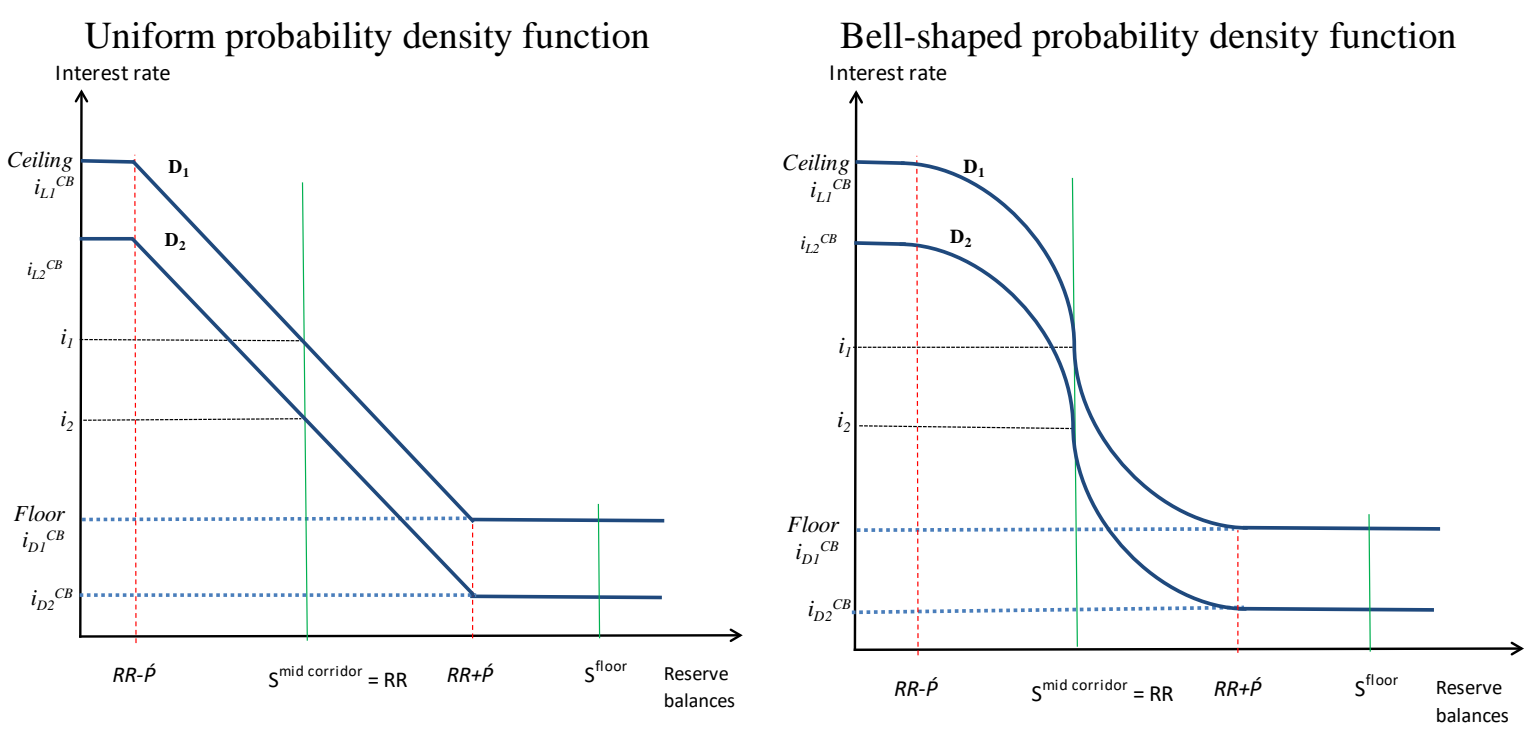

The model highlights the link between banks' demand for reserve balances, risks, and the payment system. Besides market and information failure, the risk to individual banks of becoming short or long depends crucially on: (1) the timing and coordination of interbank settlement, including gross versus net settlement, and real time versus lagged settlement; (2) the risk of large imbalances between the payment inflows and outflows during the day and at the end of the day; and (3) the timing of the closure of the payment system and the interbank market, and the risk of having to make (receive) payments after the closure of the interbank market. The risk of individual banks facing a late in the day payment shock that cannot be offset in the market can be sharply reduced by ensuring sufficient time for interbank trading to take place after the closure of retail clearing.

\section{Generalizations}

The above discussion can be extended to cover financial systems with no well-functioning interbank market, no central bank intraday credit facilities, or with interest charges on intraday central bank credit:

- No or poorly functioning interbank market. The rate on short-term government securities or central bank OMO instruments may in this case be more relevant than the interbank rate as the opportunity cost of holding excess reserves. Banks that are long, instead of being able to choose between holding excess reserves and lending it to the market, banks then can choose between holding excess reserves or buying short-term (government or OMO) securities in the primary or secondary security market. ${ }^{4}$ Banks that are short would face a similar choice of bidding for the central bank's liquidity-injecting OMOs or risk having to access the costlier standing lending facility. The basic structure of the problem

\footnotetext{
${ }^{4}$ Ennis and Weinberg (2007) discusses a version of the above model that assumes this to be the choice banks face.
} 
would in either case be the same as above, although banks would also have to consider the effect of their liquidity management decisions, not only for their overnight position, but for their positions over a more prolonged period. The degree of liquidity of those longer-term instruments and the frequency of central bank OMOs would be important factors in that regard. ${ }^{5}$

- No central bank intraday credit facilities. Banks in this case would have to factor in not only the risk of an after-the-end-of-the-trading day payment outflow, but also the risk that during the next day they could face a payment outflow that is larger than its stock of reserves. This case can be analyzed with the same model apparatus as above by redefining the assumed payment shock to include this risk.

- Interest charges on intraday credit. The expected costs of daylight credit can in this case provide a floor for the interbank market rate. This because banks would not want to lend at rates below the expected cost of daylight credit, since the expected daylight credit fees then would be larger than the interest earned on the interbank lending. ${ }^{6}$

The above model can be extended in various other directions, by incorporating the impact of reserve averaging, bank heterogeneity, market frictions and segmentations, transaction costs, and prudential regulations. ${ }^{7}$ While these can have a significant impact on banks' demand for liquid assets, interest rate volatility, and the slope of the shorter end of the yield curve, the basic insight from the above model remains valid. Bech and Keister (2013) found, however, that the maturity structure of the central bank OMOs can have a large impact on market rates, and by implication on market rate volatility, when liquidity coverage ratios are binding.

\section{The Aggregate Market Model}

The above model explains individual bank's behavior in response to an exogenously given overnight interbank market interest rate, but does not fully explain how the market rate is determined. Besides the individual payment shock risks, there is a risk of the market in aggregate ending up being long or short at the end of the day. This can happen if the central bank fails to anticipate and fully offset the autonomous flows during the day. If the market in aggregate ends up short, some banks, even in a perfect market and with perfect liquidity management capacity, will be forced to borrow from the central bank, as the other bank would not be sufficiently long. Similarly, if the system in aggregate ends up long, some banks will have to end the day with excess reserves.

\footnotetext{
${ }^{5}$ Tobin (1982) presents a model that links a bank's demand for reserves, or "defensive assets," directly to its lending decisions that also cover the case of no interbank market and where the central bank lending and deposit rates directly represent the alternative cost of lending.

${ }^{6}$ See Ennis and Weinberg (2007) for a model discussion of this.

${ }^{7}$ See in particular Bartolini, Bertola, and Prati (2001, 2002), Gaspar, Perez-Quiros, and Rodriguez-Mendizábal (2004), Whitesell (2006a), Ennis and Keister (2008), and Bech and Keister (2013).
} 
With perfect knowledge, banks that are long should be able to charge close to the central bank lending rate if the market in aggregate is short, as the only other option for the borrowing bank would be to borrow from the central bank, which would be costlier, even when the market rate is only a few basis points below the central bank lending rate Similarly, with perfect knowledge, banks should be able to borrow at close to the central bank deposit rate when the system is long.

However, banks typically must make their trading decisions without any knowledge about whether the market will end the day short or long. If the perceived probability of the market ending the day short or long is even, the risk-neutral strategy for a lender should be to aim to trade at a rate in the middle of the interest rate corridor, as then if the market ends short the profit lost would equal the profit gained if the market instead ends long. The risk-neutral strategy for a borrower should for the same reason also be to aim to trade at a rate in the middle of the interest rate corridor. If all market participants believe that there is a 50 percent chance that the market ends short and a 50 percent chance that the market ends long, and their bargaining power is equal, the market clearing interest rate should also be in the in the middle of the corridor. More generally, this line of reasoning results in the following relationship between the market clearing rate, the central bank lending and deposit standing facility rates, and the perceived probability that the market ends long or short:

$$
i=i_{L}^{C B} \cdot P(\text { short })+i_{D}^{C B} \cdot P(\text { long }), P(\text { short })+P(\text { long })=1
$$

That is, the market clearing interest rate become a stochastic variable, and equal to the weighted average of the two standing facility rates with the weights being the perceived probability that the market in aggregate at the end of the day will be short or long. ${ }^{8}$ Note the similarity of equations 5 and 7. Both imply that the interbank rate would be equal to the weighted average of the standing facility rates, with, respectively, the probability of the individual bank or market being short or long as weights.

The perceived probability of the market ending short or long would be a function of several factors. These include: the market participants' understanding of the central bank's operating target, its operating framework, and the reasons for its open market operations; the central bank's commitment to managing aggregate excess reserves so that interbank rates are kept persistently in line with the policy rate; and the central bank's track record in delivering this outcome. The risk of the central bank making large and systematic intervention errors can be significantly reduced by undertaking the OMO late in the day when the sign and size of the autonomous flows are known, instead of in the morning as has been the conventional

\footnotetext{
${ }^{8}$ See Bindseil (2004b) for a further discussion of this “aggregate market model.” See also Woodford (2001) for a model that combines the individual bank model and the aggregate market model, and Gaspar, Perez-Quiros, and Rodriguez-Mendizábal (2004) for a model that combines this with reserve averaging, market segmentation, and heterogeneity.
} 
practice. ${ }^{9}$ This should help ensure that the market participants perceive the probability of the market ending long or short is even, and thus help reduce volatility in the market rate.

${ }^{9}$ This will also help reduce the demand on high-frequency liquidity forecasting. 


\section{Appendix III. Monetary Policy Transmission Channels}

\section{A. Introduction}

Monetary policy mainly works through its impact on interest rates, explicit and implicit yields, liquidity risk, the exchange rate, and expectations. This does not mean that what is commonly referred to as the (narrow) "interest rate channel” dominates or is particularly strong, nor does it imply that "money does not matter" or that targeting money aggregates may not be a viable policy strategy. It reflects the fact that all, or almost all, of the transmission channels discussed in the literature-including the credit, bank lending, wealth, risk appetite, and bank capital channels - work through the impact of monetary policy on interest rates, liquidity risk, the exchange rate, and explicit or implicit asset yields, or by propagating and amplifying the effect of changes in these (Figure 2), ${ }^{1}$ and not by rationing the means of payment. There is a broad consensus in the literature, moreover, that consumption and investment demand are mainly a function of income, interest rates, wealth, and the availability of credit, and not money balances. Although money-in-utility models that do not assume that the utility function is separable give a structural, or causal, role for real money balances in determining demand, the consensus is that this effect would be quantitatively small and largely irrelevant. ${ }^{2}$

Modern central banks, however, do not directly control the retail rates, assets prices, and yields that ultimately determine economic behavior. What they do control is the supply of "central bank money," 3 of which only their control over one part, reserve balances, is used as a policy tool. ${ }^{4}$ However, these balances can be tiny compared to the size of the daily payment flows and the financial market, at least in countries without reserve requirements. Moreover, these balances can only be used for interbank transactions. Thus, to fully understand the transmission mechanism, it is essential to understand how the central bank's actions with regard to the volume and terms of their supply of these balances impact bank behavior, and how these actions transmit, through arbitrage, to market interest rates and assets prices.

\section{B. Reserve Balances, the Payment System, and the Interbank Money Market-the First Stage of the Transmission Mechanism}

\footnotetext{
${ }^{1}$ Bernanke and Gertler (1995) make a similar observation when they explain that they “don't think of the credit channel as a distinct, free-standing alternative ... but rather as a set of factors that amplify and propagate conventional interest effects” (page 28).

2 See, among others, Nelson (2002, 2003), Ireland (2004), Berger and others (2008), Andrés and others (2009), and Zanetti (2012).

${ }^{3}$ Equal to currency in circulation and commercial banks' deposits at the central bank ("reserve balances," for short). Government deposits at the central bank are excluded from the standard definition of reserve money.

${ }^{4}$ Modern central banks do not use their currency-issuance monopoly as a policy tool. They always supply the full amount demanded, because not doing so would impair the payment flows.
} 
Commercial banks use their deposits at the central bank - their reserve balances-for interbank transactions, particularly for settling payments they undertake on behalf of their customers. ${ }^{5}$ These deposits, as do all deposits, constitute a closed system. Banks cannot unilaterally change the amount of reserve balances in the system, nor can they transfer or lend them to anyone that does not have an account at the central bank. They can only directly use them to transact with the central bank and central bank account holders (mainly other banks and the government) to: (1) settle interbank payments; (2) purchase or sell foreign exchange or government securities; and (3) lend to the other account holders. Most of these transactions just move reserve balances from one account to another without changing the total stock of reserves in the system. The total stock of reserves held by banks can only change through transactions with non-bank account holders. ${ }^{6}$

Thus, banks' demands for reserve balances are closely linked to the working of the payment system and the central bank's liquidity management framework. Banks receive, and make, a large number of interbank payments during each day. To be able to carry out these payments, banks need to have some assets that can be transferred easily-or be able to obtain or provide credit from or to the counterparty bank. While for each bank the net of these payment flows during the day may be close to zero, there is always a risk of becoming short and not being able to carry out payments or meet reserve requirements, or of having to access the central bank's standing lending facility. This can be costly, but so can holding large unremunerated balances at the central bank that could have been lent to banks that were short. Banks' demand for reserve balances beyond required reserves is a function of these two risk or cost factors, as discussed in Appendix II.

It is possible to operate the system with a close-to-zero aggregate overnight reserve balance target, and some central banks at times have done so. ${ }^{7}$ The Reserve Bank of New Zealand for a time operated with a constant overnight reserve target of US\$20 million. Similarly, Bank of England for a time operated with a constant overnight reserve target of \&45 million, during a period in which the daily interbank payment flows were over $£ 150$ billion. Bank of Canada also operated with a zero target for overnight settlement balances for a short period, and subsequently with a small positive target, in their Large Value Settlement system ${ }^{8}$. Operating with a close-to-zero target for overnight balances does require, however, having a narrow

\footnotetext{
${ }^{5}$ For instance, when Bank A transfers money on behalf of a customer from the customer's deposit account in Bank A to someone else's deposit accounts in Bank B, Bank A would have to either transfer an asset to Bank $\mathrm{B}$ - the economically most effective way to do so would be transfers of reserve balances through the central bank’s settlement system-or obtain a credit from Bank B.

${ }^{6}$ See also Disyatat (2008), Keister and McAndrews (2009), and Bernhardsen and Kloster (2012).

${ }^{7}$ See, among others, Henckel, Ize, and Kovanen (1999) and Freedman (2000b).

${ }^{8}$ See, among others, Frazer (2005) and Nield (2006) for a discussion of the earlier liquidity management framework in New Zealand before that country moved to the current floor system with a tiered deposit facility; Tucker (2004) for a discussion of the earlier BOE framework; and Clinton (1997) and Howard (1998, with subsequent updates) for a description of the earlier Bank of Canada framework.
} 
interest rate corridor, solid liquidity forecasting, frequent OMOs, a well-functioning interbank market, well-coordinated payment settlements, proper coordination between the closure of the payment system and the interbank market, effective collateral handling, and ample access to intra- and inter-day credit facilities. ${ }^{9}$

Banks do not need to hold large reserve balances and the central bank doesn't necessarily have to change the aggregate supply of reserves for it to be able to steer the interbank rate. As discussed in Appendix II, banks' demand for overnight excess reserves should be close to zero in a mid-corridor system with symmetric risks, and it should be sufficient under that system (and under a floor system) to simply change the rates on the central bank's standing facilities, which would then cause the demand schedule for reserve balances to shift.

\section{Reserve Balances and Bank Lending: the Interest Rate, Credit, Bank Lending, and Bank Capital Transmission Channels}

\section{Introduction}

Banks in aggregate do not strictly need reserve balances at the central bank in order to lend in a modern credit economy, and, contrary to the presentation in many elementary textbooks, neither do they need deposits in order to lend. First, deposits are not an asset that banks can on-lend: it is a liability —an "I Owe You” (IOU). Second, deposits, and by implication broad money, or "commercial bank money," are created when banks engage in lending. ${ }^{10}$ When banks lend "money" to their customers, the first thing that happens is that they simultaneously create a claim on the customer and a claim for the customer on the bank in the form of a deposit (an IOU). In that sense, the lending is self-financed and banks do "print money" (although not without limits as explained in Tobin [1963]). ${ }^{11}$ Moreover, although the borrower would likely shortly thereafter use the new deposit-money created by the loan to purchase something from someone, the bank may not need any reserve balances to settle this payment if: (1) the transaction is with another account holder at the same bank; (2) all banks expand their businesses at the same pace so that each bank's increased payment outflows are matched by increased payment inflows; or (3) the bank can draw on existing interbank credit lines. ${ }^{12}$ In this case the supply of loans and the associated supply of deposit-money in the banking system would be determined primarily by interest rates and credit demand, as argued

\footnotetext{
${ }^{9}$ Both New Zealand and Bank of Canada during this period operated with a $+/-25$ bps interest rate corridor.

${ }^{10}$ See, among others, McLeay, Radia, and Thomas (2014) for a recent discussion of money creation in the modern economy.

${ }^{11}$ Similarly, when bank customers reduce their deposits to repay loans or buy financial assets such as securities and equity instruments from banks, “deposit-money” or “commercial bank money” is destroyed.

12 This is very much in line with Wicksell’s (1898) pure credit economy (see Boianovsky and Trautwein, 2006).
} 
by the post-Keynesian endogenous money school, ${ }^{13}$ and not by any limits to the supply of reserves.

However, banks do in practice need to hold reserves and other highly liquid "defensive" assets to manage the liquidity risks associated with the liability side of their balance sheets. Banks always face the risk of payment outflows that may not be fully matched by simultaneous payment inflows, as well as the risk of larger deposit withdrawals. To insure against the risk that such events could result in payment defaults or the need for costly liquidation of loans or other non-liquid assets, banks do need, and often are required, to hold defensive assets - mainly reserves and government securities - that could either directly be used for settling interbank payments, be quickly exchanged for payment means ("liquidated") at relatively low costs, or used as collateral for central bank or interbank market borrowing. For the same reason, banks would typically try to lock in part of the liability side of their balance sheet, including by offering higher-earning time deposits or issuing longer-maturity debt obligations. In this sense, banks do need funding in order to lend.

The total stock of reserves in the system can of course provide an upper limit to how much banks' balance sheets can expend, as in the classic money-multiplier theory, if banks are required to hold reserves in proportion to the size of their liabilities. ${ }^{14}$ With reserve requirements, liquidity risks (the probability of having to access the central bank's lending facility or default on interbank payments) would increase as banks' balance sheets expand and excess reserves are reduced, unless the central bank responds by injecting more reserves into the system. With a perfectly functioning interbank market, the increased liquidity risk would be fully reflected in a corresponding increase in the interbank interest rate. In the case of non-functioning, or a poorly functioning interbank market, it would instead be reflected in an increase in the shadow price on liquidity and the liquidity risk premium.

\footnotetext{
${ }^{13}$ See, among others, Moore (1988), Palley (2002, 2013), Bindseil and König (2013), and Culham and King (2013).

${ }^{14}$ This does not imply that the money-multiplier theory (and loanable fund theory) is correct and that there is a quantity-of-reserves based transmission channel. The money-multiplier story is based on a pure cash or commodity-money economy and not one dominated by deposit-money. See Humphrey (1987) on the history of the money-multiplier theory and, among others, Moore (1988), Lombra (1992), Palley (2002, 2013), Disyatat (2008, 2011), Carpenter and Demiralp (2012), Bindseil and König (2013), Culham and King (2013), McLeay, Radia, and Thomas (2014), and Jakab and Kumhof (2015) for a critique of the money-multiplier theory and of the loanable fund theory.
} 


\section{The Direct Interest Rate Channel}

The direct interest rate channel is often weak in developing countries. Its strength depends on the degree of pass-through from monetary policy actions to lending, deposit, and security rates, and on the interest rate sensitivity of investment and consumer spending decisions. Unclear policy signals and high risks may weaken the pass-through, and low financial inclusion-low credit-to-GDP ratios, low deposit-to-GDP ratios, and large shares of the population without bank accounts-may reduce the relevance of bank lending and deposits for investment financing and consumption smoothing.

There should be a strong link between monetary policy actions and lending, deposit, and security rates in a low-risk environment with well-developed financial markets and clear and relevant policy signals:

- Lending rates should be closely linked to the central bank's policy rate, or standing facility rates, in such an environment. Banks generally lend whatever is demanded as long as the expected net return is positive. The expected net return would be positive as long as lending rates, adjusted for perceived credit risks, are higher than the bank's marginal (opportunity) cost of providing the loan. ${ }^{15}$ The latter should be close to the central bank's policy rate in systems with a relevant policy rate. When expanding their lending, banks can choose to cover the expected additional interbank payment outflow by: (1) drawing on their reserve balances; ${ }^{16}$ (2) borrowing from other banks or drawing on established credit lines; (3) reducing their holding of securities by selling them to other banks or the central bank, or not rolling them over at maturity; or (4) attracting new deposits by offering better terms. ${ }^{17}$ The full (opportunity) cost of each option should in equilibrium be equal, and equal to the policy rate/interbank rate.

- Deposit rates should for the same reason also be closely linked to retail lending rates and the policy rate, as well as to security rates in this environment. Although banks create deposits when they lend, and thus "print money," the public would need to be willing to hold the additional liquidity created. The public can, as noted, on its own reduce the stock of deposits, and thus broad money, by repaying loans or buy higher yielding, but less liquid, financial assets from banks. ${ }^{18},{ }^{19}$ Thus, in well-functioning markets, deposit rates and rates on the public's other financial assets should also tend to be well aligned.

\footnotetext{
${ }^{15}$ See Tobin (1982), Bertocco (2006), and Palley (2013) for some simple, and very similar, models of this.

${ }^{16}$ Or liquidate some other defensive assets, which in either case would leave the size of their balance sheet unchanged.

${ }^{17}$ And thereby requiring other banks to transfer reserves to them in order the settle the deposit transfer.

${ }^{18}$ Purchases of securities from domestic nonbank entities would not reduce the total stock of deposits in the system but only shift them from the bank account of the buyer to the seller of the securities.

${ }^{19}$ Because of this and the credit-demand driven supply of deposit-money described above, deposits, and thus broad money would in the end be endogenously determined by the interplay of money demand and the supply
} 
- Commercial banks' demand for government securities should strengthen the link between monetary policy and security yields. While banks cannot lend out their reserve balances, they can use them to buy securities from the government and from each other. Moreover, because government securities in most cases can be used as collateral for obtaining shortterm funding from the central bank or the interbank market, ${ }^{20}$ they are a close substitute to reserve balances as “defensive” assets. For this reason, interbank rates and short-term government security yields typically are closely correlated.

- The existence of well-developed capital markets would strengthen the link between security yields and bank lending and deposit rates. This by providing larger entities with alternatives to bank loans for funding investments, by providing banks with alternative funding sources, and by providing the public with alternatives to deposits for placing their funds.

However, this direct transmission channel can be fairly weak in high-risk environments with underdeveloped financial markets, weak credit culture, limited contract enforceability, and unclear monetary policy signals and operations, because:

- Banks rely more on customer relationships, collateral, and other non-price factors for determining lending, and as a result can be slower to pass on changes in the policy stance, in such an environment. While banks should still want to lend as long as the expected net return is positive, they may not fully price in the risks of lending to less well-known borrowers because of risk of adverse selection (only high-risk borrowers would borrow when rates are too high) or because there is little or no reliable information regarding borrowers' creditworthiness. Lenders therefore incur costs in establishing trustworthy relationships and may be reluctant to pass on small increases in the policy rate or their funding costs to existing borrowers because of the risk that they could sever those relationships or cause the borrower to default. Similarly, banks may be able to delay passing on a decline in interest rates as borrowers may have few alternatives in the short-term, due to the time required to establish another banking relationship. ${ }^{21}$

- Relatively small changes in the policy rate may be absorbed by changes in the risk premium when those are a high proportion of the total retail lending rate. The consequence is that the threshold for changing the pricing on existing loans may be higher, thereby blunting policy transmission. When combined with weak competition in the banking sector, the resulting wide spread between deposit and lending rates reduces pressure on banks to reprice loans and deposits, further undermining transmission.

- Unclear monetary policy signals and inappropriate operations increase risks, fragment markets, reduce bank competition, and slow the pass-through of changes in the policy

of commercial bank money created by bank lending, as argued by the Structuralist camp within the postKeynesian School.

${ }^{20}$ Through repurchase arrangements or collateralized loans.

${ }^{21}$ See, among others, Aksoy, Basso, and Coto-Martinez (2013). 
stance. Banks’ liquidity situations and liquidity risks, and thus their marginal (opportunity) costs of providing a loan, may differ substantially if they cannot routinely place surplus liquidity or obtain short-term funding at rates that are reasonably stable and predictable. Big differences in marginal opportunity costs would tend to weaken bank competition and fragment the markets, particularly so in an environment with high credit risk.

There may still be a strong link between monetary policy and government security yields in such a high risk, unclear policy environment. Banks typically are dominant players in the government securities market in these economies. While the secondary market may be inactive and these instruments thus fairly illiquid, banks can use them as collateral for obtaining short-term funding from the central bank or the interbank market. Thus, they can still serve as a close substitute to reserve balances in the banks' portfolio of liquid "defensive” assets. For the same reason, government security yields, in place of interbank rates, often serve as the formal, or de facto, pricing-base for bank loans and deposits in countries with no policy rate and no or highly volatile interbank rates.

\section{Monetary Policy, Lending Risk, Asset Prices, and the Wealth and Credit Channels}

Changes in interest rates affect households' and businesses' cash-flow and cause asset prices to change, both of which may affect the demand for credit and banks' willingness to lend. ${ }^{22}$ As is well documented, persistent changes in asset prices do impact consumption, saving, and investment decisions, including through the "wealth effect" on household consumption and the market value/book value ratio for commercial enterprises. Changes in asset prices also change the strength of borrowers' balance sheets and the value of any collateral they may pledge, which would impact on the actual, or perceived, risk banks are taking and thus their willingness to lend, and the risk premium they would require. Changes in borrowers' cashflow positions impact their creditworthiness and the risk premium banks would demand. Changes in cash-flow positions may, in addition, directly affect the real economy by changing liquidity-constrained households' consumption demand and liquidity-constrained small businesses' ability to expand their operations. Interest rate changes would also affect the cost of businesses' working capital and thus their operating costs. Finally, the changes in the overall economic environment and outlook caused by a change in the monetary policy stance would impact the perceived riskiness of lending and thus banks' willingness to lend. These effects would amplify the impact of monetary policy actions on the real economy, but could also give rise to destabilizing asset bubbles.

\footnotetext{
${ }^{22}$ See, among others, Bernanke and Gertler (1995), Bernanke, Gertler, and Gilchrist (1996), and Bernanke (2007).
} 


\section{Monetary Policy and the Risk Channel}

Interest rate changes may directly impact banks risk appetite, risk perception, and willingness to lend, and thereby further amplify the impact of monetary policy actions on the real economy, through:

- Credit rationing in a high interest rate environment. As noted in the discussion of the direct interest rate channel, above, high interest rates may give rise to an adverse selection effect. Thus, rather than raising interest rates, banks may instead prefer to curtail credit. While this may weaken the direct interest rate channel, it would act as an amplifier of monetary policy impulses to the real economy.

- Search for yields and higher risk appetite in a low interest rate environment. Low returns on existing lending projects may increase the incentive for lenders to take on more risk to boost profit. ${ }^{23}$ This tendency would act as an amplifier of monetary policy impulses to the real economy in a low interest rate environment, but also as a source of potential financial risk and instability.

- Observed volatility and measures of risk. A change in the policy rate that impacts asset and collateral values may in turn change estimates of the probability of default, of lossgiven-default, and of volatility. For example, low interest rates and increasing asset prices tend to reduce asset price volatility and thus risk perception. ${ }^{24}$

\section{Capital Requirements and the Bank Lending Channel}

Monetary policy may also affect bank lending and lending rates through its impact on the strength of banks' balance sheets. ${ }^{25}$ Banks, for prudential reasons, are subject to capital requirements and thus may have to raise additional capital as they lend and expand the asset side of their balance sheet. In the same way as asset prices and the strength of nonbank balance sheets may affect their creditworthiness and borrowing costs, the strength of banks' balance sheets can affect their ability to raise capital, and/or the cost of doing so, as well as their access to, and the cost of, short-term uninsured market funding. Because of this, bank capital, and bank capital requirements, may affect the monetary policy transmission by: ${ }^{26}$

\footnotetext{
${ }^{23}$ See, among others, the findings of Gambacorta (2009), Dell’Ariccia, Laeven, and Suarez (2013), and Jiménez and others (2014) and the discussion in Borio and Zhu (2012).

${ }^{24}$ Gambacorta (2009).

${ }^{25}$ See, among others, Van den Heuvel (2002), Gambacorta and Mistrulli (2004), Honda (2004), Kishan and Opiela (2006), Disyatat (2011), Kapan, and Minoiu (2013). See also Bernanke (2007) for recognition that "fundamentally, the bank-lending channel is based on the quality of bank balance sheets..."

${ }^{26}$ See, in particular, Kishan and Opiela (2006) for evidence of the impact of bank capital shortages on banks' response to monetary policy changes and the asymmetric response of capital-weak banks to expansionary versus contractionary policy changes.
} 
- Changing the strength of banks' balance sheets and thereby their funding costs. This effect may be stronger in well-developed financial systems where banks may rely more on uninsured market funding than in developing countries. ${ }^{27}$

- Hampering weaker banks' ability to expand their lending in response to a monetary policy loosening. This because costs of raising additional capital (both in the form of equity and borrowed capital) may be prohibitively high.

- Causing weaker banks to more sharply contract lending in response to a monetary tightening.

This effect of monetary policy via its impact on banks' financial health could work both by amplifying the effect of changes in short-term interest rates on lending rates (effectively an amplification of the interest rate channel) or by changing banks' lending standards and their use of non-price measures for granting loans.

Note that this bank capital version of the "bank lending channel" differs from the version discussed in the older literature and in the textbooks. There are two variants of the older version of the bank lending channel:

- The first, following Bernanke and Blinder (1988) was based on the money multiplier theory. It assumes that a reduction in aggregate reserves, because of reserve requirements, would force banks to reduce deposits and that this would then reduce their ability to lend, and that therefore there exists a direct quantity-based link from central bank reserve management to bank lending. There are a number of fundamental problems with this theory. The assumed individual bank behavior should result in a negative correlation between deposit rates and lending and money market rates, which is the opposite of what is observed. A bank that, in response to a shortage of reserves, actively tries to reduce its deposits would, moreover, face an even sharper reserve shortage as depositors withdraw their funds. Contrary to what is being here assumed, banks typically respond to a monetary tightening and a shortage of reserves by bidding up interest rates on deposits in order to protect their deposit and reserve holdings or to obtain additional reserves by attracting new deposits. While a tightening could cause a decline in bank loans and deposits, the direction of causality would be the opposite of what is assumed under the original bank lending channel—from interest rates to lending and from lending to deposits.

- The second, newer version, assumes that banks might respond to a reduction in the supply of reserves by replacing reservable deposits with non-reservable liabilities. This literature also takes as a starting point that a reduction in the stock of reserves would force banks to reduce the stock of reservable deposits. ${ }^{28}$ If banks, due to regulations, are

\footnotetext{
${ }^{27}$ See Disyatat (2011).

${ }^{28}$ See, among others, Kishan and Opiela (2000), Kashyap and Stein (2000), and Ehrmann and others (2001).
} 
prevented from paying interest on reservable deposits or increase the interest rate offered, as was the case in the US under regulation $\mathrm{Q},{ }^{29}$ a monetary tightening that increased nonregulated interest rates relative to the rates offered on reservable deposits could indeed induce depositors to withdraw their funds and place them in higher yielding securities. This might give the impression that the transmission worked the same way as in the money multiplier theory. However, the chain of causality, even under regulation Q, would be through interest rates and not through the stock of loanable funds, as assumed in the money multiplier theory. ${ }^{30}$ Moreover, with banks now being able to freely determine the rates they offer on deposits, they would now react to a monetary tightening by increasing all deposit rates.

\section{The Exchange Rate Channel}

The strength of the exchange rate channel depends on the direct link between monetary policy and the exchange rate, and the degree of pass-through from the exchange rate to inflation and the wider economy. While many low- and middle-income countries are small and open, and partly for that reason the exchange rate pass-through may be strong, the direct link between monetary policy and the exchange rate can be weak. Besides expectation effects, there needs to be significant foreign exchange flows that are sensitive to changes in relative interest rates for there to be a strong direct link between monetary policy and the exchange rate, which may not be the case in many LLMICs. Interest-rate-sensitive crossborder capital flows are fairly limited in many LLMICs, and not only in those countries with a closed capital account. ${ }^{31}$ Thus, the exchange rate channel may be weaker than assumed in these countries. At the same time, it could be stronger than assumed in highly dollarized economies with sizable foreign currency deposits in the local banking system. Monetary policy actions that push up the rates offered on local currency deposits relative to foreign currency deposits and induce depositors to shift their deposits in the local banking system from foreign currency to local currency accounts could then also strongly affect the exchange rate.

\footnotetext{
${ }^{29}$ See the discussions in Bernanke (2007) and Boivin, Kiley, Mishkin (2010).

30 The tighter liquidity situation and higher market rates would tend to also push up security yields, which would induce some depositors to shift from deposits to securities and force banks to increase their reliance on more expensive uninsured wholesale market funding. This would again push up lending rates, which would cause a reduction in new lending, and, as a consequence, reduce the creation of new deposits.

${ }^{31}$ Limits on banks’ net open foreign exchange positions would, moreover, limit banks own-account purchases of foreign exchange.
} 


\section{References}

Aksoy, Y., H.S. Basso, and J. Coto-Martinez, 2013, "Lending Relationships and Monetary Policy,” Economic Inquiry, Vol. 51(1): 368-93.

Andrés, J., J.D. López-Salido, and E. Nelson, 2009, “Money and the natural rate of interest: Structural estimates for the United States and the euro area," Journal of Economic Dynamics and Control, Vol. 33(3): 758-76.

Bartolini, L., G. Bertola, and Alessandro Prati, 2001, "Banks reserve management, transaction costs, and the timing of Federal Reserve intervention,” Journal of Banking \& Finance, Vol. 25, Issue 7 (July): 1287-1317.

, 2002, "Day-To-Day Monetary Policy and the Volatility of the Federal Funds Interest Rate,” Journal of Money, Credit and Banking, 34 (February): 137-59.

Batten, D., M. Blackwell, I. Kim, S. Nocera, and Y. Ozeki, 1989, “The instruments and operating procedures for conducting monetary policy in the group of five countries," IMF Working Paper 89/57.

Bech, M.L., and T. Keister, 2013, "Liquidity Regulation and the Implementation of Monetary Policy,” BIS Working Paper No. 432.

Benati, L., and C. Goodhart, 2011, "Monetary Policy Regimes and Economic Performance: The Historical Record, 1979-2008, in” Handbook of Monetary Economics, Vol. 3B, eds. Benjamin M. Friedman and Michael Woodford (Amsterdam: Elsevier; NorthHolland). http://dm-edms.imf.org/cyberdocs/4384094.

Bernanke, B.S., and M. Gertler, 1995, "Inside the Black Box: The Credit Channel of Monetary Policy Transmission,” Journal of Economic Perspectives, 9(4): 27-48. , and S. Gilchrist, 1996, “The financial accelerator and the fight to quality,” The Review of Economics and Statistics, Vol. 48: 1-5.

Bernanke, B.S., and I. Mihov, 1997, “What Does the Bundesbank Target?” European Economic Review 41, No. 6 (June): 1025-53.

Bernanke, B.S., 2007, “The Financial Accelerator and the Credit Channel,” speech given at the Credit Channel of Monetary Policy in the Twenty-first Century Conference, Federal Reserve Bank of Atlanta.

Berger, H., T. Harjes, and E. Stavrev, 2008, “The Information Content of Money in Forecasting Euro Area Inflation,” IMF Working Paper WP/08/166.

Bernhardsen, T., and A. Kloster, 2010, “Liquidity management system: Floor or corridor?” Norges Bank Staff Memo No. 4, 2010.

, 2012, “Misunderstood central bank reserves,” Norges Bank Economic Commentaries No. 1, 2012.

Bertocco, G., 2006, “Some observations about the endogenous money theory,” Economics and Quantitative Methods qf0602, Department of Economics, University of Insubria.

Bindseil, U., 2004a, “The Operational Target of Monetary Policy and the Rise and Fall of Reserve Position Doctrine,” ECB Working Paper No. 372. 
, 2004b, Monetary Policy Implementation—Theory, Past and Present, Oxford UP, New York.

Bindseil, U., and F. Wuertz, 2006, "Payment systems from the monetary policy implementation perspective" in Institutional Change in the Payments System and Monetary Policy, eds. S. Schmitz and G. Wood. Routledge international studies in money and banking, 35 .

Bindseil, U., and K.G. Nyborg, 2007, "Monetary policy implementation: A European Perspective," NHH Department of Finance \& Management Science Discussion Paper No. $2007 / 10$.

Bindseil, U., and J. Jabłecki, 2011a, "The optimal width of the central bank standing facilities corridor and banks’ day-to-day liquidity management,” ECB Working Paper No. 1350.

, 2011b, “A structural model of central bank operations and bank intermediation,” ECB Working Paper No. 1312.

Bindseil, U., 2011, Monetary Policy Operations and the Financial System, Oxford UP, New York.

, and P.J. König, 2013, “Basil J. Moore’s Horizontalists and Verticalists: an appraisal 25 years later," Review of Keynesian Economics, Vol. 1, No. 4, Winter: 383-90.

Boianovsky, M, and H.M. Trautwein, 2006, "Wicksell after Woodford,” Journal of the History of Economic Thought, Vol. 28, Issue 02: 171-85.

Boivin, J., M.T. Kiley, and F.S. Mishkin, 2010, "How Has the Monetary Transmission Mechanism Evolved over Time?” Finance and Economics Discussion Series, No. 2010-26, Board of Governors of the Federal Reserve System, Washington, DC.

Borio, C.E.V., 1997, “Monetary policy operating procedures in industrial countries,” BIS Working Paper No. 40.

, and H. Zhu, 2012, "Capital regulation, risk-taking and monetary policy: a missing link in the transmission mechanism?” Journal of Financial Stability, Vol. 8, Issue 4 (December): 236-51.

Bowman, D., E. Gagnon, and M. Leahy, 2010, "Interest on Excess Reserves as a Monetary Policy Instrument: The Experience of Foreign Central Banks," Board of Governors of the Federal Reserve System International Finance Discussion Papers No. 996.

Carpenter, S., and S. Demiralp, 2006a, "Anticipation of Monetary Policy and Open Market Operations," International Journal of Central Banking 2(2) (June): 25-63.

, 2006b, "The Liquidity Effect in the Federal Funds Market: Evidence from Daily Open Market Operations,” Journal of Money, Credit and Banking 38: 901-20.

, 2008, "The Liquidity Effect in the Federal Funds Market: Evidence at the Monthly Frequency," Journal of Money, Credit and Banking 40: 1-24.

, 2012, "Money, reserves, and the transmission of monetary policy: does the money multiplier exist?” Journal of Macroeconomics, Vol. 34, No. 1: 59-75. 
Clinton, K., 1997, "Implementation of monetary policy in a regime with zero reserve requirements,” Bank of Canada Working Paper No. 97-8.

Cottarelli, C., and A. Kourelis, 1994, "Financial Structure, Bank Lending Rates, and the Transmission Mechanism of Monetary Policy,” Staff Papers-International Monetary Fund, Vol. 41, No. 4 (December): 587-623.

Culham, J., and J.E. King, 2013, “Horizontalists and Verticalists after 25 years,” Review of Keynesian Economics, Vol. 1, No. 4, Winter: 391-405.

Dell’Ariccia, G., L. Laeven, and G. Suarez, 2013, “Bank Leverage and Monetary Policy’s Risk-taking Channel: Evidence from the United States,” IMF Working Paper 13/143.

Disyatat, P., 2008, “Monetary policy implementation: Misconceptions and their consequences,” BIS Working Paper No. 269.

, 2011, “The Bank Lending Channel Revisited,” Journal of Money, Credit and Banking Vol. 43, Issue 4 (June): 711-34.

Ehrmann, M., L. Gambacorta, J. Martínez-Pagés, P. Sevestre, and A. Worms, 2001, "Financial systems and the role of banks in monetary policy transmission in the Euro Area,” ECB Working Paper No. 105.

Ennis, H.M., and J.A.Weinberg, 2007, “Interest on Reserves and Daylight Credit,” Federal Reserve Bank of Richmond Economic Quarterly, Vol. 93, Spring: 111-42. , and T. Keister, 2008, “Understanding Monetary Policy Implementation,” Federal Reserve Bank of Richmond Economic Quarterly, Vol. 94, Summer: 235-63.

Frazer, J., 2005, “Liquidity management in the New Zealand banking system,” Reserve Bank of New Zealand Bulletin, Vol. 67, No. 4.

Freedman, C., 2000a, "Monetary aggregates and monetary policy in the twenty-first century: Discussion," in The evolution of monetary policy and the federal system over the past thirty years: a conference in honor of Frank E. Morris, eds. R.W. Kopcke and L.E. Browne, Federal Reserve Bank of Boston, Conference Series, 45,3: 1-41. , 2000b, "Monetary Policy Implementation: Past, Present and Future-Will Electronic Money Lead to the Eventual Demise of Central Banking?” International Finance, Vol. 3, Issue 2 (July): 211-27.

Friedman, B.M., 2000, “The Role of Interest Rates in Federal Reserve Policy Making,” in The evolution of monetary policy and the federal system over the past thirty years: a conference in honor of Frank E. Morris, eds. R.W. Kopcke and L.E. Browne, Federal Reserve Bank of Boston, Conference Series, 45,3: 43-65.

, and K.N. Kuttner, 2011, "Implementation of Monetary Policy: How Do Central Banks Set Interest Rates?” in Handbook of Monetary Economics, Vol. 3B, eds. Benjamin M. Friedman and Michael Woodford (Amsterdam: Elsevier; North-Holland). http://dmedms.imf.org/cyberdocs/4384094.

Gagnon, J.E., and B. Sack, 2014, "Monetary Policy with Abundant Liquidity: A New Operating Framework for the Federal Reserve Policy,” Peterson Institute for International Economics, Policy Brief PB14-4. 
Gambacorta, L., and P.E. Mistrulli, 2004, “Does bank capital affect lending behavior?” Journal of Financial Intermediation.

Gambacorta, L., 2009, “Monetary policy and the risk-taking channel,” BIS Quarterly Review (December): 43-53.

Gaspar, V., G. Perez-Quiros, and H. Rodriguez-Mendizábal, 2004, “Interest Rate Determination in the Interbank Money Market,” ECB Working Paper, No. 351.

Goodfriend, M., 2002, “Interest on Reserves and Monetary Policy,” Federal Reserve Bank of New York Economic Policy Review 8 (May): 77-84.

Guthrie, G., and J. Wright, 2000, “Open Mouth Operations,” Journal of Monetary Economics 46 (October): 489-516.

Gray, S., 2011, “Central Bank Balances and Reserve Requirements,” IMF Working Paper WP/11/36.

, and N. Talbot, 2006, "Monetary Operations," Handbooks, Centre for Central Banking Studies, Bank of England, number 24.

Gray, S., P. Karam, V. Meeyam, and M. Stubbe, 2013, Monetary Issues in the Middle East and North Africa Region: A Policy Implementation Handbook for Central Bankers, IMF Departmental Paper No. 13/1.

Henckel, T., A. Ize, and A. Kovanen, 1999, “Central Banking Without Central Bank Money,” IMF Working Paper WP/99/92.

Honda, Y., 2004, “Bank capital regulations and the transmission mechanism,” Journal of Policy Modeling 26: 675-688.

Howard, D., 1998, “A Primer on the Implementation of Monetary Policy in the LVTS Environment,” Bank of Canada Review (Autumn): 57-66.

Humphrey, T.M., 1987, “The theory of multiple expansions of deposits: what it is and when it came,” Federal Reserve Bank of Richmond Economic Review 2: 3-11.

International Monetary Fund, 2015, "Evolving Monetary Policy Frameworks in Low-Income and Other Developing Countries,” IMF Policy Paper.

Ireland, P.N., 2000, “Interest Rates, Inflation, and Federal Reserve Policy since 1980,” Journal of Money, Credit and Banking, Vol. 32(3): 417-34.

, 2004, “Money's role in the monetary business cycle," Journal of Money, Credit and Banking, Vol. 36: 969-83.

Jakab, Z., and M. Kumhof, 2015, "Banks are not intermediaries of loanable funds-and why this matters,” Bank of England Working Papers, No. 529.

Jimenez, G., S. Ongena, J. Peydro, and J. Saurina, 2014, “Hazardous Times for Monetary Policy: What Do Twenty-Three Million Bank Loans Say About the Effects of Monetary Policy on Credit Risk Taking?” Econometrica 82:463-505.

Kapan, T., and C. Minoiu, 2013, "Balance Sheet Strength and Bank Lending during the Global Financial Crisis,” IMF Working Paper WP/13/102. 
Kashyap, A.K., and J.C. Stein, 2000, "What Do a Million Observations on Banks Say About the Transmission of Monetary Policy,” American Economic Review, Vol. 90, No. 3: 407-28.

, 2012, “The Optimal Conduct of Monetary Policy with Interest on Reserves,” American Economic Journal, Macroeconomics, 4(1): 266-82.

Keister, T., A. Martin, and J. McAndrews, 2008, “Divorcing Money from Monetary Policy,” Federal Reserve Bank of New York, Economic Policy Review 14 (September): 4156.

, 2015, "Floor Systems and the Friedman Rule: The Fiscal Arithmetic of Open Market Operations” Federal Reserve Bank of New York Staff Report No. 754.

Keister, T., and J. McAndrews, 2009, “Why are banks holding so many excess reserves?” Federal Reserve Bank of New York Staff Report 380.

King, M.A., 1994, “Monetary policy in the UK,” Fiscal Studies 15, No. 3: 109-128.

Kishan, R.P., and T.P. Opiela, 2000, "Bank Size, Bank Capital, and the Bank Lending Channel,” Journal of Money, Credit and Banking, Vol. 32: 121-41.

Kishan, R., and T. Opiela, 2006, "Bank capital and loan asymmetry in the transmission of monetary policy,” Journal of Banking and Finance, 30: 259-85

Laurens, B.J., K. Eckhold, D. King, A. Naseer, N. Maehle, and A. Durré, 2015, “The Journey to Inflation Targeting: Easier Said than Done. The Case for Transitional Arrangements along the Road,” IMF Working Paper WP/15/136.

Lombra, R., 1992, “Understanding the remarkable survival of multiplier models of money stock determination,” Eastern Economics Journal, Vol. 18, No. 3.

McCallum, B.T., 1981, "Price Level Determinacy with an Interest Rate Policy Rule and Rational Expectations,” Journal of Monetary Economics, 8: 319-29.

McLeay, M., A. Radla, and R. Thomas, 2014, “Money creation in the modern Economy,” Bank of England Quarterly Bulletin, Q1.

Mishkin, F.S., and A.S. Posen, 1997, "Inflation Targeting: Lessons from Four Countries,” Federal Reserve Bank of New York Economic Policy Review (August): 9-110.

Moore, B.J., 1988, Horizontalists and Verticalists: The Macroeconomics of Credit Money, Cambridge, New York and Melbourne: Cambridge University Press.

Nelson, E., 2002, “Direct effects of base money on aggregate demand: theory and evidence," Journal of Monetary Economics, Vol. 49: 687-708. , 2003, “The future of monetary aggregates in monetary policy analysis,” Journal of Monetary Economics, Vol. 50: 1061-70.

Nield, I., 2008, “Evolution of the Reserve Bank’s liquidity facilities,” Reserve Bank of New Zealand Bulletin, Vol. 74, No. 4.

Palley T., 2002, “Endogenous money: what it is and why it matters,” Metroeconomica, Vol. 53: $152-80$. 
, 2013, "Horizontalists, verticalists, and structuralists: the theory of endogenous money reassessed,” Review of Keynesian Economics, 1(4): 406-24.

Poole,W., 1968, “Commercial Bank Reserve Management in a Stochastic Model: Implications for Monetary Policy,” Journal of Finance, 23: 769-91.

, 2000, "Monetary aggregates and monetary policy in the twenty-first century, in The evolution of monetary policy and the federal system over the past thirty years: a conference in honor of Frank E. Morris, eds. R.W. Kopcke and L.E. Browne, Federal Reserve Bank of Boston, Conference Series, 45: 12-24.

Sargent, T., and N. Wallace, 1975, “"Rational’ Expectations, the Optimal Monetary Instrument, and the Optimal Money Supply Rule,” Journal of Political Economy, Vol. 83, Issue 2: 241-54.

Sellon, G.H., 1982, “Monetary targets and inflation: the Canadian experience.” Federal Reserve Bank of Kansas City Economic Review, April: 16-31.

Svensson, L.E.O., 1997, "Inflation forecast targeting: Implementing and monitoring inflation targets,” European Economic Review, 41: 1111-46.

Tobin, J., 1963, "Commercial Banks as Creators of 'Money,’” in Banking and Monetary Studies, eds. Deane Carson and R.D. Irwin.

, 1982, “The Commercial Banking Firm: A Simple Model,” The Scandinavian Journal of Economics, Vol. 84, No. 4: 495-530.

Thornton, D., 2004, “The Fed and short-term rates: Is it open market operations, open mouth operations or interest rate smoothing?” Journal of Banking \& Finance, Volume 28, Issue 3, March: 475-98.

Tucker, P., 2004, "Managing the Central Bank’s Balance Sheet: Where Monetary Policy Meets Financial Stability,” lecture delivered to mark the Fifteenth Anniversary of Lombard Street Research.

Van den Heuvel, S.J., 2002, “Does bank capital matter for monetary policy transmission?” Economic Policy Review, Federal Reserve Bank of New York: 259-65.

Whitesell, W., 2006a, “Interest-rate Corridors and Reserves,” Journal of Monetary Economics, 53: 1177-95. , 2006b, "Monetary policy implementation without averaging or rate corridors," Finance and Economics Discussion Series, No. 2006-22. Board of Governors of the Federal Reserve System.

Woodford, M., 2001, "Monetary Policy in the Information Economy,” in Economic Policy for the Information Economy, Federal Reserve Bank of Kansas City.

Zanetti, F., 2012, "Banking and the role of money in the business cycle," Journal of Macroeconomics, 34: 87-94. 